\title{
Cardanol and Eugenol Based Flame Retardant Epoxy Monomers for Thermostable Networks
}

\author{
Yvan Ecochard ${ }^{1,+}{ }^{\dagger}$, Mélanie Decostanzi ${ }^{1, \dagger}$, Claire Negrell ${ }^{1, *}$, Rodolphe Sonnier ${ }^{2}$ and \\ Sylvain Caillol ${ }^{1}$ (1) \\ 1 ICGM, UMR 5253-CNRS, Université de Montpellier, ENSCM, 240 Avenue Emile Jeanbrau, 34296 \\ Montpellier, France; yvan.ecochard@enscm.fr (Y.E.); melanie.decostanzi@gmail.com (M.D.); \\ sylvain.caillol@enscm.fr (S.C.) \\ 2 C2MA, IMT-Mines Alès, 6, avenue de Clavières, 30100 Alès, France; rodolphe.sonnier@mines-ales.fr \\ * Correspondence: claire.negrell@enscm.fr \\ + These authors contributed equally to this work.
}

Received: 10 April 2019; Accepted: 7 May 2019; Published: 10 May 2019

check for updates

\begin{abstract}
Epoxy materials have attracted attention for many applications that require fireproof performance; however, the utilization of hazardous reagents brings about potential damage to human health. Eugenol and cardanol are renewable, harmless resources (according to ECHA) that allow the achievement of synthesis of novel phosphorylated epoxy monomers to be used as reactive flame retardants. These epoxy building blocks are characterized by ${ }^{1} \mathrm{H}$ NMR and ${ }^{31} \mathrm{P} N M R$ (nuclear magnetic resonance) and reacted with a benzylic diamine to give bio-based flame-retardant thermosets. Compared to DGEBA (Bisphenol A Diglycidyl Ether)-based material, these biobased thermosets differ by their cross-linking ratio, the nature of the phosphorylated function and the presence of an aliphatic chain. Eugenol has led to thermosets with higher glass transition temperatures due to a higher aromatic density. The flame-retardant properties were tested by thermogravimetric analyses (TGA), a pyrolysis combustion flow calorimeter (PCFC) and a cone calorimeter. These analyses demonstrated the efficiency of phosphorus by reducing significantly the peak heat release rate (pHRR), the total heat release (THR) and the effective heat of combustion (EHC). Moreover, the cone calorimeter test exhibited an intumescent phenomenon with the residues of phosphorylated eugenol thermosets. Lastly, the higher flame inhibition potential was highlighted for the phosphonate thermoset.
\end{abstract}

Keywords: cardanol; eugenol; epoxy; thermoset; flame retardant

\section{Introduction}

Epoxy thermosets are among the most used polymers in the world due to their excellent chemical, thermal, mechanical and dielectric properties. They are found in many applications such as coatings, adhesives, composites and high performance materials [1-3]. Despite this broad range of applications, most of the epoxy monomers used are obtained from oil-based resources and may cause several issues in terms of health and environmental concerns. Indeed, Bisphenol A diglycidyl ether (DGEBA), which results from the reaction between bisphenol A and epichlorohydrin, is the major epoxy precursor [4]. However, bisphenol A is an endocrine disruptor and a "carcinogenic, mutagenic and reprotoxic" (CMR) substance [5,6]. Furthermore, epichlorohydrin is also a classified CMR substance. Thus, in terms of sustainable development, synthesizing biobased and less harmful aromatic monomers for epoxy thermosets has become a major challenge in the last few years [7-11], especially to replace DGEBA. Hence, the interest around renewable phenols has recently grown in both industry and academia. Indeed, several works have been reported in the literature on vanillin [12], lignin [13,14], cardanol $[7,8]$, eugenol $[15,16]$ and their derivatives. With different functionalized sites, biobased 
phenols can be transformed into new monomers to create very promising thermosets with high renewable content and high thermo-mechanical properties. Indeed, their phenol functions can be used to obtain dimers or trimers, increasing the functionality of monomers. Furthermore, biobased phenols bearing unsaturation can be easily oxidized into epoxy monomers without the use of epichlorohydrin. In this context, eugenol and cardanol seem to be very attractive molecules for the synthesis of epoxy monomers. Eugenol is generally obtained either from cloves (of which the main product is clove oil: $80 \mathrm{wt} . \%$ ) or from lignin by enzymatic reactions [17]. It has been used for high rigidity epoxy thermosets for different applications requiring a high heat resistance and low flammability [16]. Cardanol is also interesting because it's a non-edible phenolic oil obtained from cashew nutshell, a side-product of the cashew industry, and is often used to obtain soft materials due to its aliphatic chain. It is considered to be one of the most promising renewable aromatic by-products, relatively cost-effective and available.

In order to increase both aromatic density and thermal stability, biobased epoxy trimers have been obtained using a phosphorus linker $\left(\mathrm{POCl}_{3}\right)$ and phenols by our team [18]. Furthermore, phosphorus atoms are well known to improve flame retardancy in condensed phases and/or gas phases [19-21]. Many studies were led on phosphorus-containing epoxy materials and their ability to improve flame retardant properties [22-24]. Cardanol was already used as an additive for biobased flame retardants by Pillai et al. through phosphorylation and oligomerization [25]. The obtained prepolymer presents high reactivity with amines, aldehydes and isocyanates and promising properties as a flame-retardant additive. Fu et al. showed also the efficiency of cardanol-based zirconium phosphate as a flame-retardant additive for epoxy composite [26]. However, a reactive optimization way was developed by Wazarkar and Sabnis using phosphorylated cardanol based dimers as curing agents [27]. Thermogravimetric analyses, UL94 and limiting oxygen index (LOI) tests on coatings highlight, in this study, the good flame-retardant properties and a synergistic effect of phosphorus and sulphur atoms mainly on the char production. Around $2 \mathrm{wt} . \%$ of phosphorus and $4.6 \mathrm{wt} . \%$ of sulphur lead to UL94 V0 rating, but LOI is only slightly enhanced from 20 to 22 . Alternately, the flame retardant properties of tri(epoxized-eugenyl)phosphate (TEEP) cured with diaminodiphenylmethane (DDM) have been analyzed by Miao et al. and compared to DGEBA based thermosets [28]. TEEP-DDM thermoset reaches UL94 V0 rating, a LOI of 31.4 and a low pHRR of $119 \mathrm{~W} / \mathrm{g}$ in PCFC. Only a few studies have been carried out to show the fireproof and mechanical effectiveness of phosphorus functions associated with biophenols to propose new thermosets with a high added value.

The aim of this work is to design biobased epoxy monomers based on eugenol and cardanol to prepare thermosets with a high phosphorus content and two oxidation degrees of phosphorylated functions. Indeed, the presence of the phosphorus atom inside the network allows to obtain excellent intumescent properties without the loss of thermo-mechanical properties, the major drawback of the addition of flame-retardant additives to thermosets. Furthermore, the reactive way prevents migration of flame-retardant compounds out of the network. This original grafting of cardanol and eugenol monomers owing to phosphorylated functions increases the functionality of biophenol monomers. Trimerization or dimerization is followed by the epoxidation of double bonds in mild conditions, before curing with a benzylic diamine (meta-xylylendiamine: MXDA) leading to materials with a high biobased content. We finally report the characterizations of those biobased high performance thermosets to evaluate the structure-properties relationship. Consequently, the impact of the phosphonate or the phosphate, the functionality as well as the influence of the structure on flame-retardant and thermo-mechanical properties have been studied.

\section{Results and Discussion}

The synthesis of four monomers with various structures, in terms of their epoxy functionality, aromatic density and phosphorus functions, was performed in order to determine the influence of these different parameters on both the thermo-mechanical and flame-retardant properties of the final materials. For this purpose, three phosphate, and one phosphonate monomers were synthesized. Phosphorus containing flame retardants exhibit different kinds of modes of action, such as flame 
inhibition in the gas phase, and char enhancement and intumescent in the condensed phase [29,30]. More specifically, phosphonate and phosphate groups are well known for their flame retardant activity mainly in the condensed phase as char promoters, while phosphinate and phosphine oxides have a significant gas phase activity but a lower ability to promote char [31,32]. Furthermore, phosphates are reported to have the best efficiency in char promotion [32].

\subsection{Monomers Characterization}

Three monomers from eugenol (Scheme 1) and one from cardanol (Scheme 2) have been synthesized following our previous synthesis pathway [18]. In both cases, the first reaction is a nucleophilic substitution of the chloride by the phenol group. With the use of $\mathrm{POCl}_{3}$ the monomer formed has a functionality of 3 while the use of $\mathrm{POCl}_{2} \mathrm{Ph}$ or $\mathrm{POCl}_{2}(\mathrm{OPh})$ leads to a functionality of 2 . The epoxidation reaction was then performed. Meta-chloroperoxybenzoic acid ( $m$-CPBA) was used for the epoxidation reaction of allylic function of eugenol, whereas hydrogen peroxide was used for the epoxidation of internal unsaturations of cardanol. Due of the toxicity of $m$-CPBA, the use of hydrogen peroxide was favored when relevant. In fact, hydrogen peroxide is used for the epoxidation of internal unsaturations whereas $m$-CPBA is used for terminal unsaturations [33].

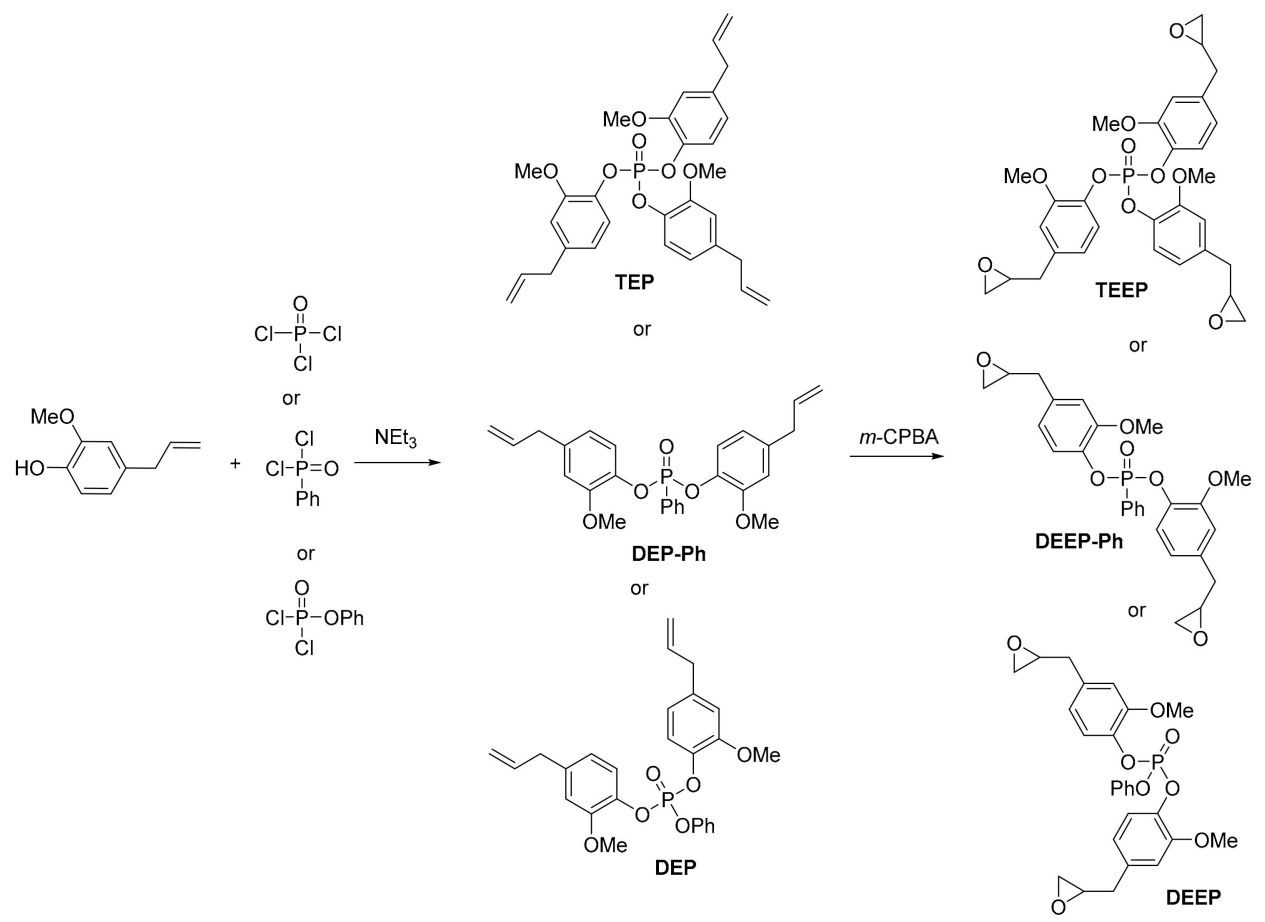

Scheme 1. Synthesis pathway for eugenol-based monomers.

The structures of the three new monomers, DEEP, DEEP-Ph and TECP (TEEP was already reported [18]) were characterized by ${ }^{1} \mathrm{H}$ and ${ }^{31} \mathrm{P}$ NMR. The ${ }^{1} \mathrm{H}$ NMR of the TEEP monomer and all the ${ }^{31} \mathrm{P}$ NMR are in the Supplementary Materials (Figures S1-S10). Figure 1 shows the stacked ${ }^{1} \mathrm{H}$ NMR spectra of eugenol, dieugenylphosphate (DEP) and di(epoxized-eugenyl)phosphate (DEEP). In the spectra of eugenol, the signals at 6.7 and $6.9 \mathrm{ppm}$ were assigned to aromatic protons $a, b$ and $c$. The protons of the double bond can be found at $5.0(\mathrm{~g})$ and $5.9 \mathrm{ppm}(f)$ as multiplets. The methoxy protons $(d)$ were localized at $3.8 \mathrm{ppm}$ and finally the allylic protons $(e)$ were observed at $3.3 \mathrm{ppm}$. In the spectrum of DEP, only a few changes are observed. Indeed, the aromatic protons ( $a$ ) are deshielded when the hydroxyl function is grafted onto the phosphate. Furthermore, the signals of the benzene protons were observed at 7.1-7.2 ppm $\left(j_{1}\right)$ and at 7.3-7.4 ppm $\left(i_{1}\right.$ and $\left.h_{1}\right)$. Finally, in the spectrum of DEEP, the disappearance of both olefinic and allylic protons was observed. They were replaced by the 
epoxy protons $\left(f_{2}\right.$ and $\left.g_{2}\right)$ and by the glycidyl protons $\left(e_{2}\right)$ respectively at 3.0, 2.9 and $2.6 \mathrm{ppm}$. All of these observations confirmed the chemical structure of DEEP epoxy monomer in a quantitative yield.

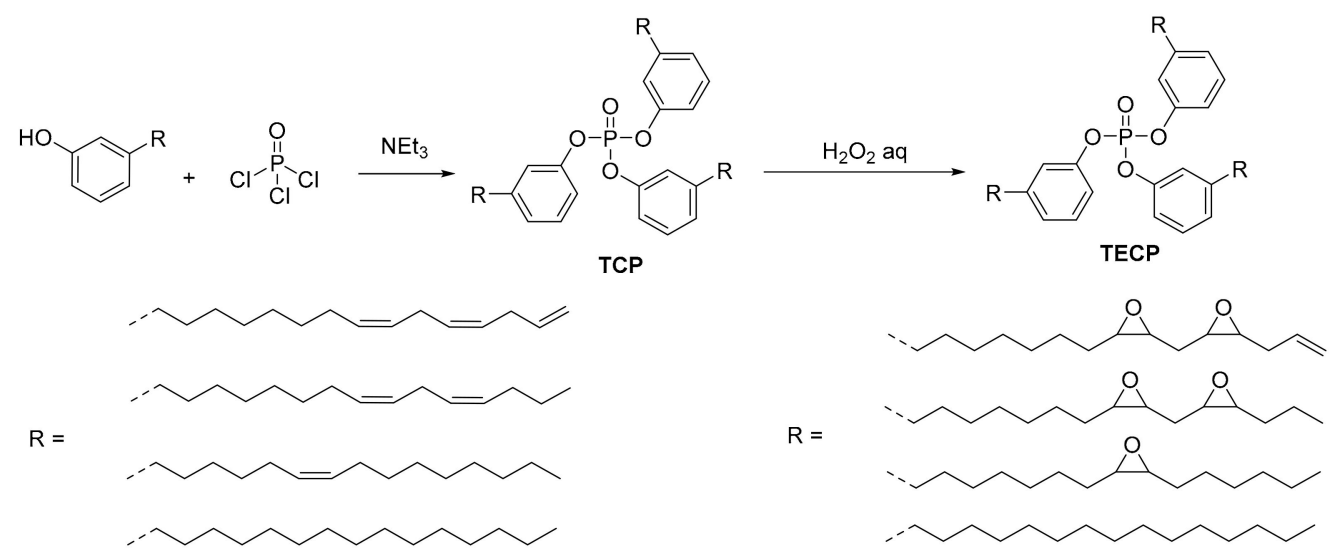

Scheme 2. Synthesis pathway for cardanol-based monomer. (Cardanol is a mixture of different molecules containing from 0 to 3 unsaturations).

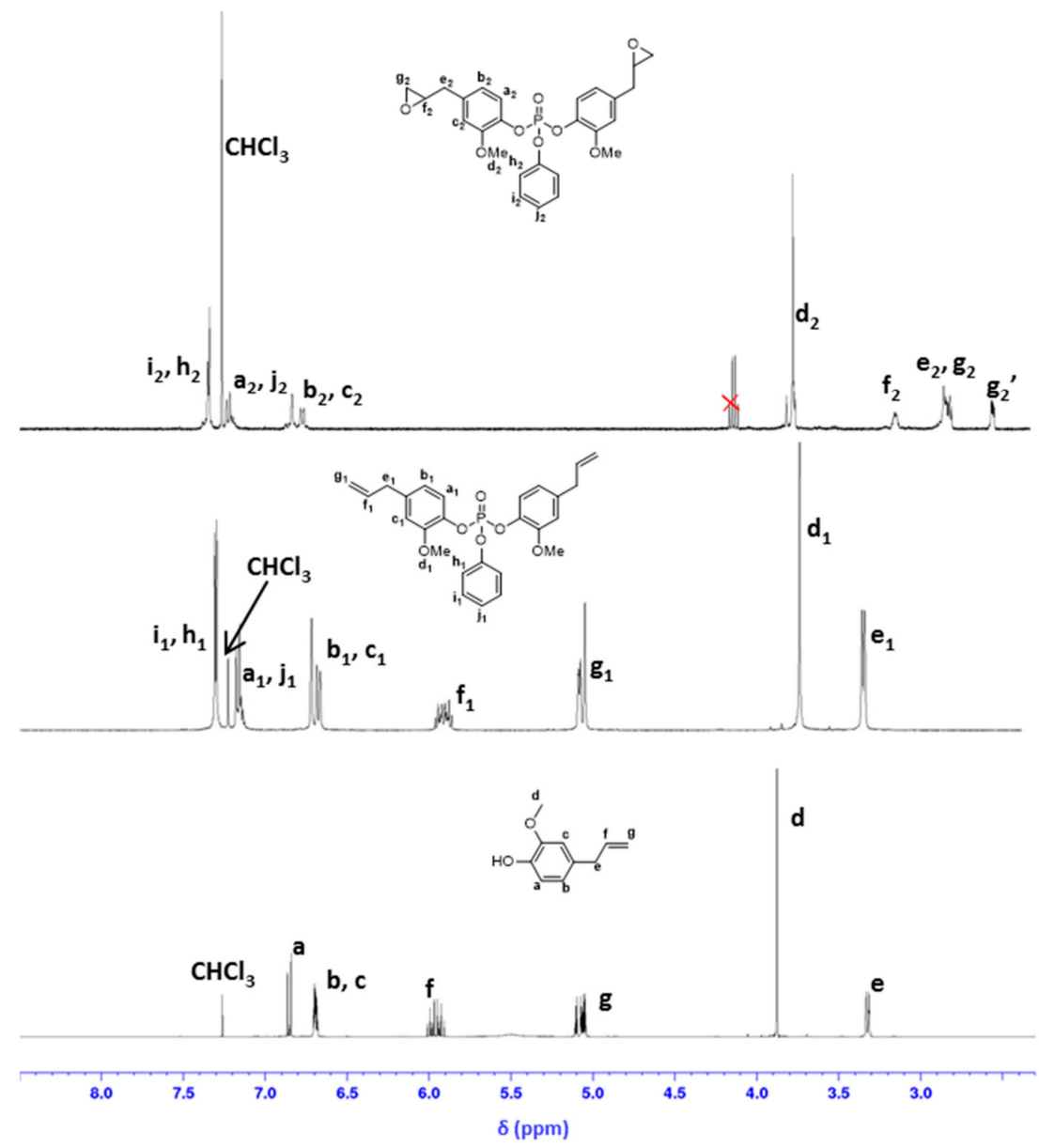

Figure 1. Stacked ${ }^{1} \mathrm{H}$ NMR spectra of: Eugenol (bottom), DEP (middle) and DEEP (top) in $\mathrm{CDCl}_{3}$.

Figure 2 shows the stacked ${ }^{1} \mathrm{H}$ NMR spectra of eugenol, dieugenylphosphonate (DEP-Ph) and di(epoxized-eugenyl)phosphonate (DEEP-Ph). In the spectrum of DEP-Ph, the aromatic protons $(a)$ are deshielded when the hydroxyl function is grafted onto the phosphonate. Furthermore, the signals of the benzene protons were observed at 7.4-7.7 ppm $\left(i_{1}\right.$ and $\left.j_{1}\right)$ and at 8.0-8.1 ppm $\left(h_{1}\right)$. Finally, in the spectrum of DEEP-Ph, the disappearance of both olefinic and allylic protons was observed. They were 
replaced by the epoxy protons $\left(f_{2}\right.$ and $\left.g_{2}\right)$ and by the glycidyl protons $\left(e_{2}\right)$ respectively at 3.0, 2.9 and $2.6 \mathrm{ppm}$.

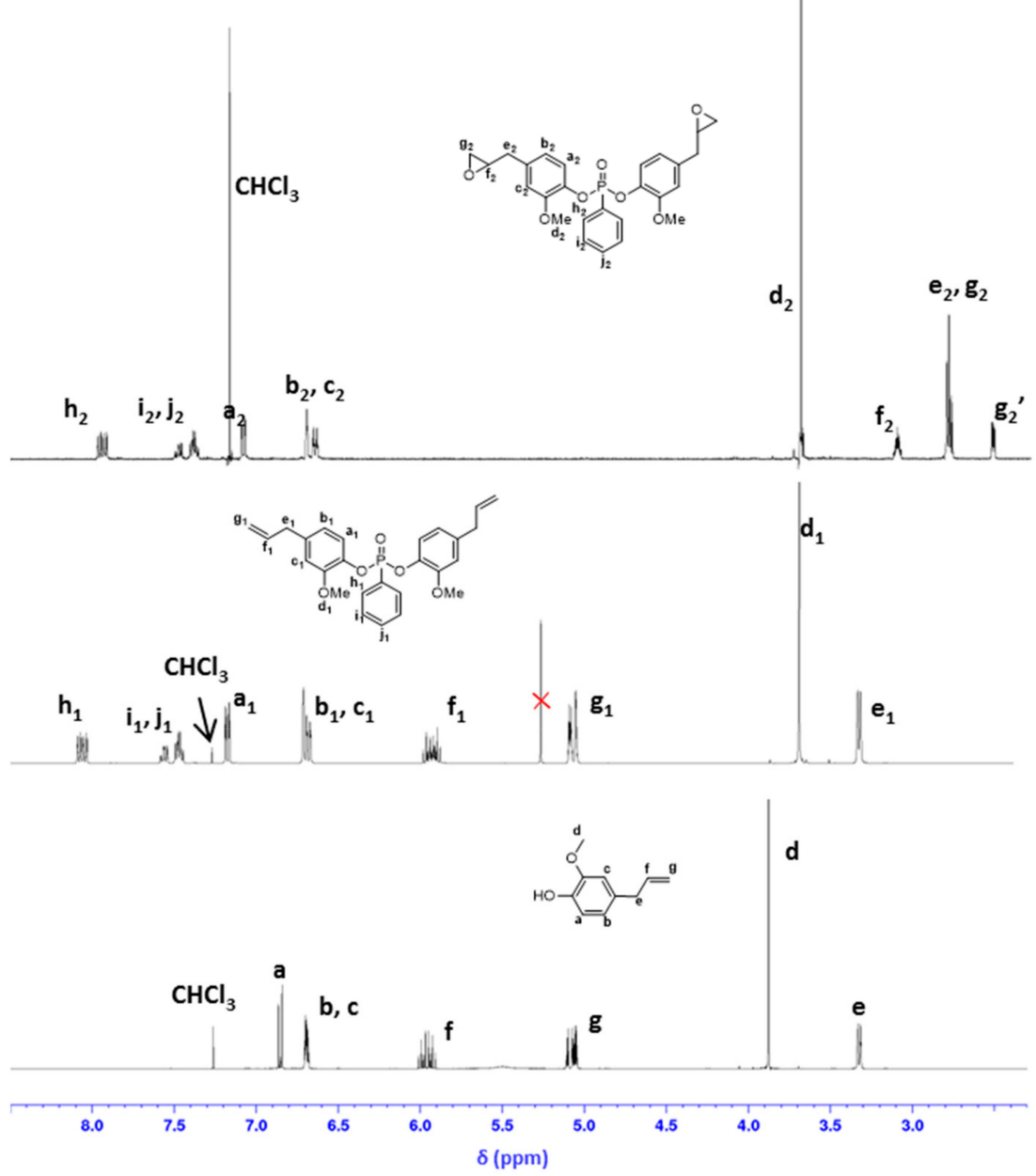

Figure 2. Stacked ${ }^{1} \mathrm{H}$ NMR spectra of: Eugenol (bottom), DEP-Ph (middle) and DEEP-Ph (top) in $\mathrm{CDCl}_{3}$.

Figure 3 shows the stacked ${ }^{1} \mathrm{H}$ NMR spectra of cardanol, TCP and TECP. In the spectrum of cardanol, the signals at 7.1, 6.8 and $6.7 \mathrm{ppm}$ were assigned to aromatic protons 13, 14, 15 and 16 . The protons of the terminal unsaturation can be found at 5.8 (2) and $5.0 \mathrm{ppm}$ (1) whereas the internal unsaturations were localized at $5.4 \mathrm{ppm}(4,5,7$ and 8$)$. The protons in $\alpha$ position of two double bonds were observed at $2.7 \mathrm{ppm}$ ( 6 and 3 ) whereas the protons in $\alpha$ position of only one double bond can be found at $2 \mathrm{ppm}\left(9\right.$ and $\left.3^{\prime}\right)$. The benzylic protons are localized at $2.5 \mathrm{ppm}(12)$. The protons at 1.6 and $1.3 \mathrm{ppm}$ were assigned to the protons of the aliphatic chain $\left(2^{\prime}, 10\right.$ and 11$)$. Finally, the saturated terminal protons $\left(1^{\prime}\right)$ were observed at $0.9 \mathrm{ppm}$. In the spectrum of TCP, the main change comes from the deshielding of the aromatic protons $\left(13_{1}, 14_{1}, 15_{1}\right.$ and $\left.16_{1}\right)$ when the hydroxyl function is grafted onto the phosphate. Finally, the internal unsaturations were epoxidized using hydrogen peroxide. Indeed, this reagent is well known to hardly epoxidize the terminal unsaturations. This result was confirmed by ${ }^{1} \mathrm{H}$ NMR. Indeed, $29 \%$ of terminal and $88 \%$ of internal double bonds were respectively epoxidized. Furthermore, the signals of the formed epoxy functions were observed at $3.0 \mathrm{ppm}$. The COSY ${ }^{1} \mathrm{H}-{ }^{1} \mathrm{H}$ NMR was used to assign all the protons (see Supplementary Materials_-Figure S11). 


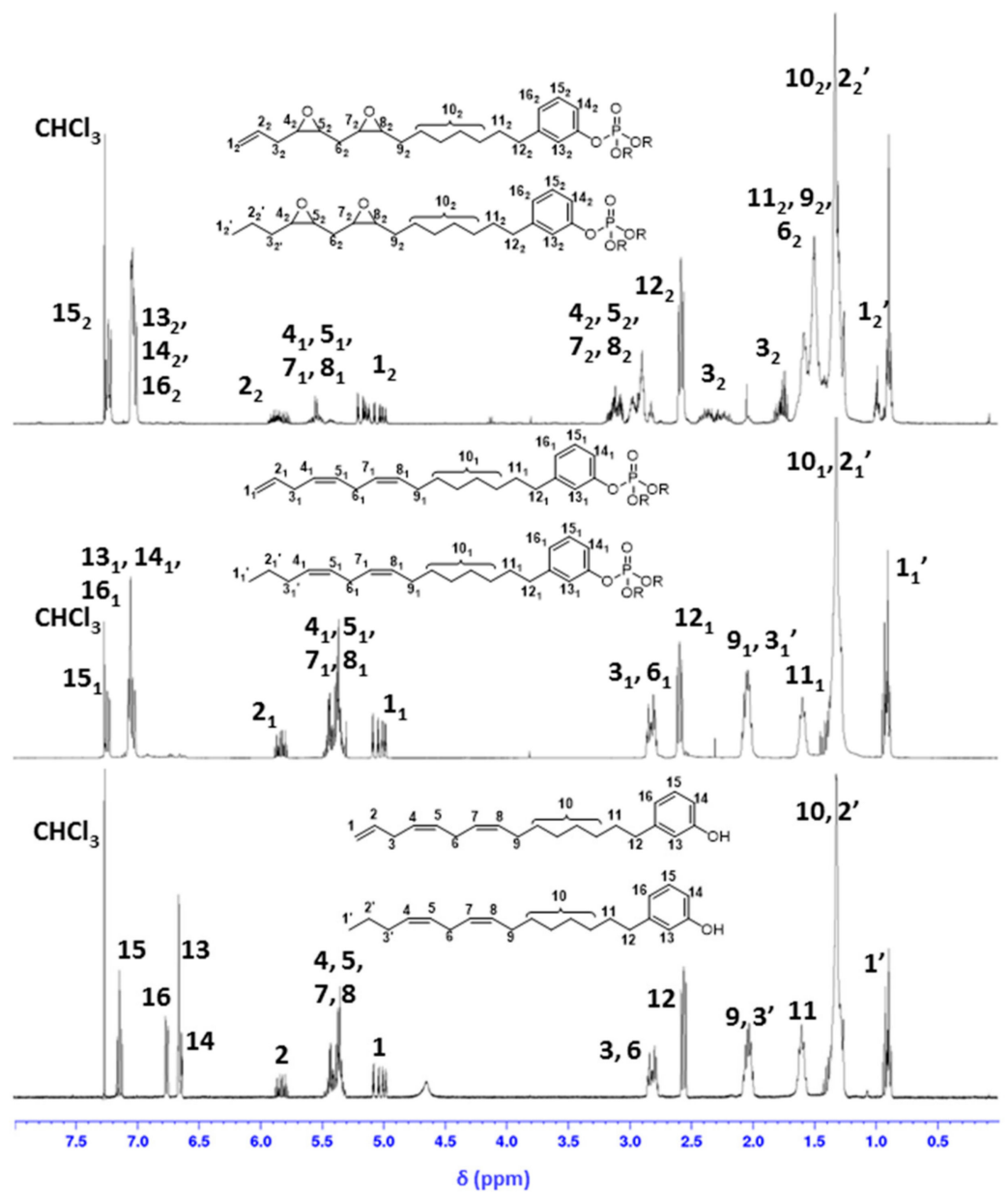

Figure 3. Stacked ${ }^{1} \mathrm{H}$ NMR spectra of: Cardanol (bottom), TCP (middle) and TECP (top) in $\mathrm{CDCl}_{3}$.

It is demonstrated that ${ }^{31} \mathrm{P}$ NMR confirmed the presence of phosphate and phosphonate functions with peaks at $-16.5,-15.9,-17.6$ and $13.0 \mathrm{ppm}$ for DEEP, TEEP, TECP and DEEP-Ph respectively.

\subsection{Characterization and Properties of Thermosets}

These four epoxy monomers have been reacted with meta-xylylenediamine (MXDA) in order to synthesize epoxy thermosets. Both phosphonate and phosphate linkers allow to bind two or three molecules together, and to form epoxy monomers with high aromatic density and functionality. The reaction of these monomers with short diamine leads to rigid thermosets.

MXDA has been selected for its compatibility with the original phosphorus-containing epoxy monomers and the stiffness conferred by the aromatic ring. Furthermore, a new biobased synthesis pathway of MXDA has been recently reported by Jérôme et al. [34]. In order to compare materials with industrial epoxy thermosets, DGEBA have been chosen for its large utilization at industrial scale and for structure similar to the synthetized monomers.

A stoichiometric ratio of two epoxy functions for one amine function was used for the synthesis of all materials. The EEW was calculated via ${ }^{1} \mathrm{H}$ NMR titration with an internal standard. The results are respectively $195 \mathrm{~g} / \mathrm{eq}$ for TEEP, $310 \mathrm{~g} / \mathrm{eq}$ for DEEP, $241 \mathrm{~g} / \mathrm{eq}$ for DEEP-Ph and $240 \mathrm{~g} / \mathrm{eq}$ for TECP.

The degree of cross-linking of the networks was characterized with gel content measurement (Table 1). The calculation methods were described in the experimental section. Gel content corresponds to the residual mass of materials after immersion in THF and drying. With values up to $99 \%$, no free species remain in the network and the cross-linking is complete for eugenol-based materials. The lower GC values of TECP materials are explained by the presence of non-crosslinked oligomer chains. Indeed, internal epoxy functions of the cardanol chain are less reactive than terminal epoxy 
functions of eugenol. More probably, cardanol is a mixture of several molecules and some of them contain saturated, non-reactive aliphatic chains that probably remain unreacted in the network.

Table 1. Thermal and thermo-mechanical properties of cured materials.

\begin{tabular}{ccccccccc}
\hline $\begin{array}{c}\text { Epoxy Monomers } \\
\text { (Cured With } \\
\text { MXDA) }\end{array}$ & $\begin{array}{c}\text { Gel } \\
\text { Content } \\
\mathbf{( \% )}\end{array}$ & $\begin{array}{c}\mathbf{T}_{\mathbf{d 5} \%} \\
\left({ }^{\circ} \mathbf{C}\right)\end{array}$ & $\begin{array}{c}\text { Char } \\
\text { Yield } \mathbf{( \% )} \\
\mathbf{a}\end{array}$ & $\begin{array}{c}\mathbf{T}_{\mathbf{g}} \\
\left({ }^{\circ} \mathbf{C}\right)\end{array}$ & $\begin{array}{c}\mathbf{T}_{\boldsymbol{\alpha}} \\
\left({ }^{\circ} \mathbf{C}\right)\end{array}$ & $\begin{array}{c}\mathbf{E}_{\text {glassy }}^{\prime} \\
(\mathbf{M P a})\end{array}$ & $\begin{array}{c}\mathbf{E}_{\text {rubbery }}^{\prime} \\
(\mathbf{M P a})\end{array}$ & $\begin{array}{c}\mathbf{v}^{\prime} \\
\left(\mathbf{m o l} / \mathbf{m}^{3}\right)\end{array}$ \\
\hline DGEBA & 99 & 333 & 7 & 116 & 130 & 1210 & 18 & 1146 \\
TECP & 82 & 311 & 12 & -26 & 18 & 1500 & 1.3 & 140 \\
TEEP & 99 & 295 & 43 & 84 & 78 & 1210 & 2.5 & 218 \\
DEEP & 100 & 300 & 41 & 98 & 94 & 2000 & 7.8 & 739 \\
DEEP-Ph & 100 & 305 & 35 & 109 & 128 & 1250 & 3.1 & 273 \\
\hline
\end{tabular}

DSC measurements have been performed on each material. The curves are summarized in Supplementary Materials (Figure S12). High glass transition temperature values are obtained with eugenol monomers. In fact, short monomers with aromatic rings led to highly cross-linked and stiff thermosets. On the opposite, the dangling chain of cardanol confers flexibility to the materials and allowed to obtain materials with lower $\mathrm{T}_{\mathrm{g}}$ values. We observed some differences for $\mathrm{T}_{\mathrm{g}}$ values which are 84,98 and $109{ }^{\circ} \mathrm{C}$ of TEEP, DEEP and DEEP-Ph materials, respectively. Values of $\mathrm{T}_{\mathrm{g}}$ are linked to the mobility of the network and are thus influenced by its rigidity but also linked to the mobility of each segment. With kneecap movements, methoxy groups have shown an important influence on the glass transition temperature of materials $[35,36]$. This can explain the drop of $\mathrm{T}_{\mathrm{g}}$ for TEEP material which possesses three methoxy groups against two for the DEEP material. This also explains the high $\mathrm{T}_{\mathrm{g}}$ of the DGEBA material around $115-120^{\circ} \mathrm{C}[37,38]$. Indeed, the weak mobility of the DGEBA monomer increases the stiffness of the network. Due to the phosphorus-carbon bond in the phosphonate group, the DEEP-Ph material presents less mobility than the DEEP material with its phosphorus-oxygen-carbon bonds. Thus, the DEEP-Ph material presents the highest $\mathrm{T}_{\mathrm{g}}$ of the eugenol-based materials.

The thermo-mechanical properties of the different materials have been compared by DMA and the results are outlined in Table 1 . The storage modulus $\left(E^{\prime}\right)$ and $\tan \delta$ as function of the temperature are shown in Figures 4 and 5. The alpha-transition temperatures have been measured at the maximum of the $\tan \delta$ for each material. With slightly higher values, $T_{\alpha}$ values followed the same trend than $T_{g}$ values measured by DSC. Narrow peaks of $\tan \delta$ for all materials, except the one with DEEP, show a good homogeneity. According to the theory of rubber elasticity [39,40], the molecular weight between the crosslinking-nodes of a cured epoxy network is proportional to its storage modulus in the rubbery region. Thus, the cross-linking density $\left(v^{\prime}\right)$ has been calculated on the rubbery domain at $150{ }^{\circ} \mathrm{C}$ for the eugenol-based materials and $100{ }^{\circ} \mathrm{C}$ for TECP. The storage modulus ( $\left.\mathrm{E}^{\prime}\right)$ on the rubbery domain is dependent on the stiffness of materials and follows the same trend as the cross-linking density $\left(v^{\prime}\right)$. As explained for DSC measurements, DGEBA leads to the stiffest materials and presents the highest values of $E^{\prime}$ rubbery, $v^{\prime}$ and $T_{\alpha}$. According to the values of $E^{\prime}$ rubbery and $v^{\prime}$ the stiffness of eugenol-based materials ranged as follows: DEEP $>$ DEEP-Ph $>$ TEEP. The order of $\mathrm{T}_{\alpha}$ for DEEP and DEEP-Ph is inverted compared to $\mathrm{E}^{\prime}$ rubbery measurements but the tendency of those results is similar to $\mathrm{T}_{\mathrm{g}}$ for which the DSC measurement and explanation has been given earlier. Such a difference in cross-linking density could therefore be explained by the presence of side reactions. Transesterification can occur with phosphate groups and high temperature of curing can promote this side reaction [41]. Phosphate groups being less stable than phosphonate groups are more able to create new bonds via this side reaction that could explain a higher cross-linking density with DEEP. Side reactions may also cause heterogeneity in materials, which could explain the broad tan $\delta$ peak with DEEP. Indeed, higher values of $E^{\prime}$ rubbery could be expected for TEEP but the higher flexibility brought by methoxy groups as well as the space between chains impact the network, and this can explain these lower values. Finally, 
TECP was the softest material due to its long and dangling aliphatic chains with a $\mathrm{E}_{\text {rubbery }}^{\prime}$ of $1.3 \mathrm{MPa}$ at $\mathrm{T}_{\alpha+50}{ }^{\circ} \mathrm{C}$ and a crosslinking density of $140 \mathrm{~mol} / \mathrm{m}^{3}$.

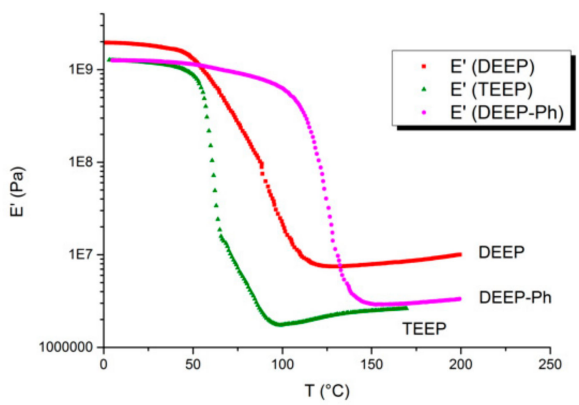

(A)

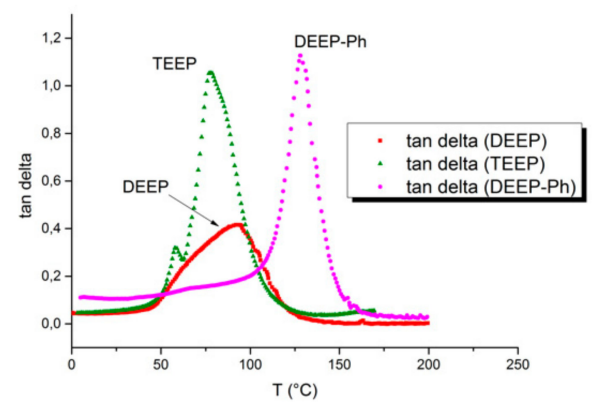

(B)

Figure 4. E' (A-left) and tan $\delta$ (B-right) of DMA curves for eugenol-based materials (red: DEEP; green: TEEP; magenta: DEEP-Ph).

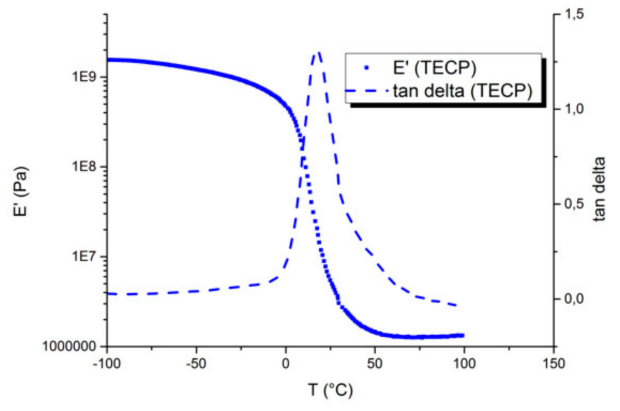

(A)

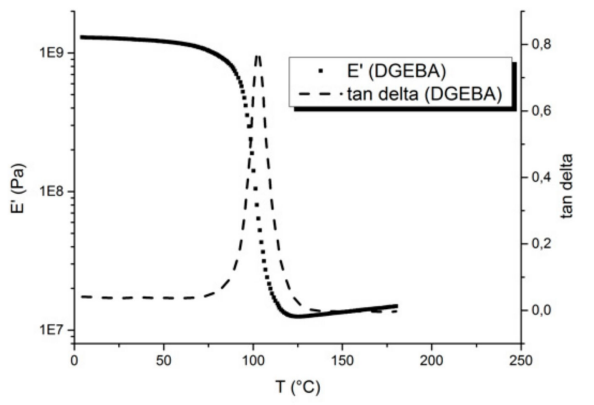

(B)

Figure 5. E' (A-left) and $\tan \delta$ (B-right) of DMA curves for cardanol-based and DGEBA-based materials (blue: TECP; black: DGEBA).

\subsection{Flame Retardancy}

Firstly, TGA measurements were carried out under nitrogen atmosphere to characterize thermal stability of the materials and the curves are shown in Figure 6A. All these degradations occurred over $300{ }^{\circ} \mathrm{C}$ given by the values of $\mathrm{T}_{\mathrm{d} 5 \%}$. These degradation temperatures were similar but slightly lower to those obtained from DGEBA. Furthermore, the char yields of DEEP, DEEP-Ph and TEEP-based materials are higher than char yields of TECP-material because they present higher aromatic densities than the cardanol formulation. In all cases, the char yields are higher compared to DGEBA-based thermoset.

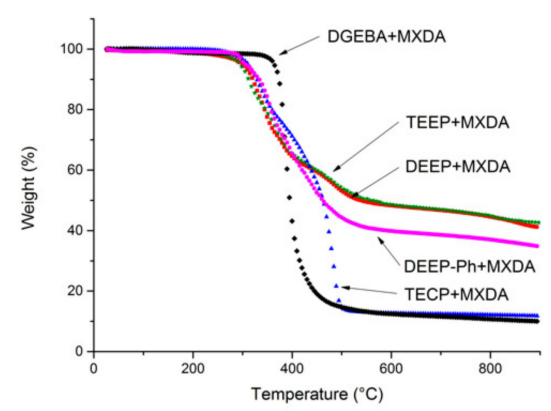

(A)

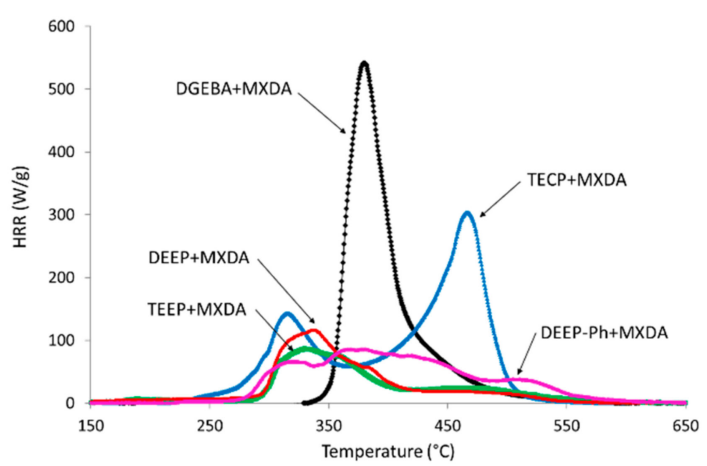

(B)

Figure 6. (A-left) Thermograms of the cured materials (B-right) Heat release rate versus temperature in pyrolysis-combustion flow calorimeter tests. 
The flame-retardancy of thermosets was then assessed using PCFC (Table 2 and Figure 6B). DGEBA-based thermoset typically exhibits high peak heat release rate (pHRR) (529 W/g) at $377^{\circ} \mathrm{C}$, high total heat release (THR) and heat of complete combustion $\Delta$ h (respectively 25.3 and $28 \mathrm{~kJ} / \mathrm{g}$ ). These values are similar to, but slightly lower than those obtained for DGEBA-IPDA thermosets [42]. The incorporation of phosphorus leads to a decrease in pHRR, THR, but also thermal stability. These tendencies are usual when phosphorus is present, especially phosphonate and phosphate groups which act as char promoters.

Table 2. Main data from pyrolysis-combustion flow calorimeter tests.

\begin{tabular}{ccccccccc}
\hline $\begin{array}{c}\text { Epoxy Monomers } \\
\text { (Cured with } \\
\text { MXDA) }\end{array}$ & $\begin{array}{c}\text { P } \\
\text { Content } \\
(\mathbf{w t .} \%)\end{array}$ & $\begin{array}{c}\text { pHRR1 } \\
(\mathbf{W} / \mathbf{g})\end{array}$ & $\begin{array}{c}\text { TpHRR1 } \\
\left({ }^{\circ} \mathbf{C}\right)\end{array}$ & $\begin{array}{c}\text { pHRR2 } \\
(\mathbf{W} / \mathbf{g})\end{array}$ & $\begin{array}{c}\text { TpHRR2 } \\
\left({ }^{\circ} \mathbf{C}\right)\end{array}$ & $\begin{array}{c}\text { THR } \\
(\mathbf{k J} / \mathbf{g})\end{array}$ & $\begin{array}{c}\text { Residue } \\
\text { Content } \\
(\mathbf{w t .} \%)\end{array}$ & $\mathbf{\Delta h}(\mathbf{k J} / \mathbf{g})$ \\
\hline DGEBA & 0 & 529 & 377 & & & 25.3 & 11 & 28.3 \\
TECP & 2.4 & 137 & 314 & 292 & 463 & 29.5 & 12 & 33.4 \\
TEEP & 4.5 & 95 & 329 & & & 9.6 & 55 & 21.1 \\
DEEP & 5.8 & 117 & 338 & & & 11.5 & 48 & 21.9 \\
DEEP-Ph & 5.8 & 88 & 366 & & & 15.3 & 35 & 23.6 \\
\hline
\end{tabular}

Interestingly HRR curves show two peaks for TECP material which may be ascribed to the heterogeneity of the network as already discussed. Another hypothesis is that the second peak corresponds to the decomposition of aliphatic chains. Indeed, the temperature of this peak is close to the decomposition temperature of polyolefins as polyethylene [43] or polypropylene. Moreover, this material does not exhibit additional charring and THR and $\triangle \mathrm{h}$ are higher compared to DGEBA thermoset. The decrease in $\mathrm{pHRR}$ is quite moderate. This may be assigned to the long aliphatic chains which are unable to char and contribute to heat release.

On the contrary TEEP, DEEP and DEEP-Ph lead to drastic decrease of pHRR and THR and strong enhancement of char. The heat of combustion is also lowered. Such high performances in comparison to TECP thermosets are due to the higher aromatic content of TEEP, DEEP and DEEP-Ph but also to the higher phosphorus content of corresponding thermosets. We observe that there is no significant difference between phosphate and phosphonate-containing materials. The DEEP-Ph thermoset exhibits a complex decomposition pathway and a very broad range of decomposition temperature $\left(270-550{ }^{\circ} \mathrm{C}\right)$ allowing an important decrease of the heat release rate in comparison to other phosphate-containing thermosets. Char yields measured by PCFC are quite close to those obtained by TGA.

In order to get an insight on our results, PCFC data are compared to other comparable data already published. While sample size in cone calorimeter is not standard, it is not possible to compare properly our results.

Flammability of epoxy depends greatly on the groups present in the network. According to literature, THR can be expected in a large range from 11 to more than $30 \mathrm{~kJ} / \mathrm{g}$ for phosphorus-free epoxy thermosets [44]. Note that in the work of Sonnier et al. a cardanol-containing epoxy thermoset exhibits a high THR and no char. This is in agreement with the present results showing that neither TECP, THR nor char content do not improve despite the presence of phosphorus.

Ménard et al. have compared the influence of phosphorus on different epoxy thermosets [45]. In this work, the phosphorus content does not exceed $3 \mathrm{wt} . \%$. Phosphorus leads to a lower pHRR and THR and higher char content but the enhancement of flame retardancy is greatly dependent on the epoxy structure. The highest improvement is observed for a DGEBA thermoset while phosphorus does not reduce greatly the heat release at microscale for phloroglucinol-containing epoxy materials which are intrinsically less flammable. Nevertheless, the peak heat release rate is significantly reduced in all cases mainly because the decomposition becomes more complex in the presence of phosphorus and occurs within a large temperature range. Thermal stability is also reduced in presence of phosphorus, which is a very common observation. 
Eugenol-based thermosets, and especially TEEP and DEEP ones, exhibit flammability data at microscale close to those obtained with a phloroglucinol-containing epoxy thermoset and difurfurylamine [45]: THR and pHRR are in the range 9-11 kJ/g and 80-120 W/g respectively depending of the phosphorus ratio (0-3 wt.\%). But, in this case, the high level of flame retardancy is achieved for high phosphorus content (4.5-5.8 wt.\%). Note also that TEEP-MXDA thermoset has flammability properties are very close to the TEEP-DDM thermoset studied by Miao et al. [28].

Cone calorimeter tests were carried out to give an insight on the flammability at bench scale (Table 3 and Figure 7A). Indeed, some phenomena, as barrier effect or flame inhibition, are not effective in PCFC standard conditions. The comparison of phosphorus-containing thermosets with the DGEBA-MXDA thermoset is only qualitative because the initial mass of the latter is slightly higher. Moreover, some phenomena are less prominent for low-weight materials, as barrier effects due to char promotion. Indeed, such materials have not a fully thermally thick behavior. Nevertheless, the differences between them are so obvious as to draw meaningful conclusions.

Table 3. Main data from cone calorimeter tests.

\begin{tabular}{|c|c|c|c|c|c|c|c|c|}
\hline $\begin{array}{l}\text { Epoxy Monomers } \\
\text { (Cured with } \\
\text { MXDA) }\end{array}$ & $\begin{array}{c}\text { P } \\
\text { Content } \\
\text { (wt. \%) }\end{array}$ & $\begin{array}{l}\text { TTI } \\
\text { (s) }\end{array}$ & $\begin{array}{c}\text { pHRR } \\
\left(\mathrm{kW} / \mathrm{m}^{2}\right)\end{array}$ & $\begin{array}{r}\text { THR } \\
(\mathrm{kJ} / \mathrm{g})\end{array}$ & $\begin{array}{c}\text { Residue } \\
\text { Content } \\
\text { (wt.\%) }\end{array}$ & $\begin{array}{c}\mathrm{EHC} \\
(\mathrm{kJ} / \mathrm{g})\end{array}$ & $\underset{(\%)}{\Delta \text { Residue }}$ & $x$ \\
\hline DGEBA & 0 & 65 & 1486 & 22.1 & 2.3 & 22.7 & -4.7 & 0.80 \\
\hline TECP & 2.4 & 31 & 708 & 20.4 & 15.4 & 24.1 & 3.4 & 0.72 \\
\hline TEEP & 4.5 & 38 & 659 & 9.5 & 40 & 15.8 & -3 & 0.75 \\
\hline DEEP & 5.8 & 39 & 593 & 9.3 & 37.5 & 14.9 & -3.5 & 0.68 \\
\hline DEEP-Ph & 5.8 & 40 & 665 & 8.4 & 32.8 & 12.5 & -2.2 & 0.53 \\
\hline
\end{tabular}

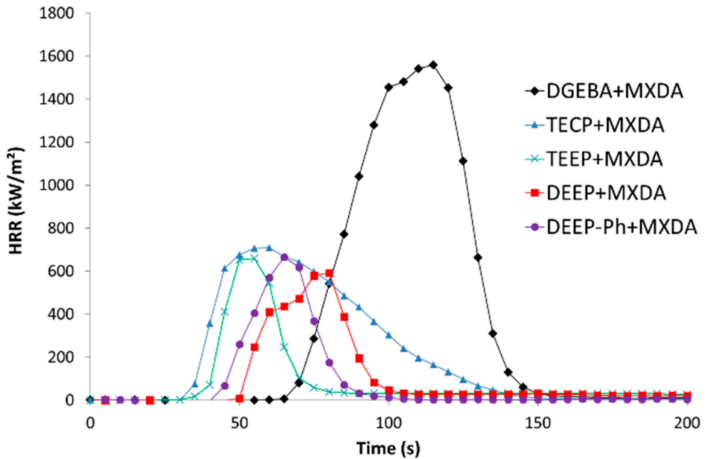

(A)

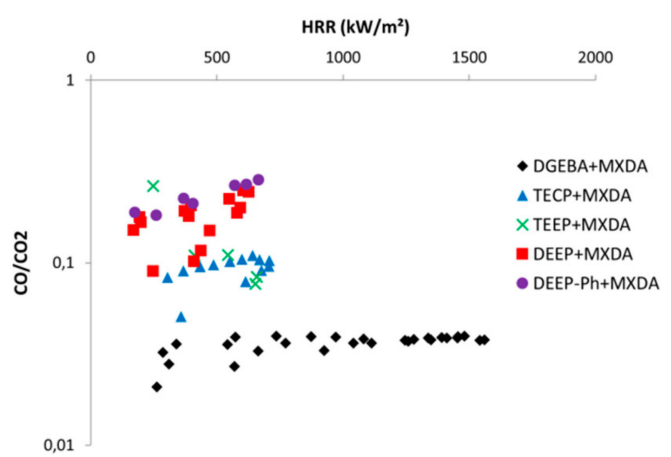

(B)

Figure 7. (A-left) Heat release rate versus time. (B-right) $\mathrm{CO} / \mathrm{CO}_{2}$ ratio versus $\mathrm{HRR}$ in cone calorimeter tests.

The DGEBA-MXDA thermoset exhibits a very high pHRR (about $1500 \mathrm{~kW} / \mathrm{m}^{2}$ ) and leaves only a small amount of char. Once again, this is similar to the fire behavior already observed for DGEBA-IPDA.

The incorporation of phosphorus leads to a significant decrease of flammability as evidenced by pHRR and THR values. Time-to-ignition is reduced with TECP, TEEP, DEEP and DEEP-Ph materials due to the decrease of thermal stability previously discussed. Once again, there are some significant differences between cardanol and eugenol-based thermosets. Actually, the phosphorylated eugenol containing thermosets possess intrinsically both lower pHRR and THR than the reference and the cardanol thermoset: they release less energy at lower release rate. The reasons for such results are discussed below.

From cone calorimeter results, the TECP thermoset shows a pHRR close to $700 \mathrm{~kW} / \mathrm{m}^{2}$, a high THR $(20.4 \mathrm{~kJ} / \mathrm{g})$ and moderate char content (15.4 wt.\%). Interestingly, TECP and DGEBA thermosets have the same char content at microscale (10-12 wt.\%) but a large difference is observed in Cone Calorimeter tests (15.4 wt.\% and $2.3 \mathrm{wt} . \%$, respectively). This is due to the presence of phosphorus which improves 
the thermo-oxidative stability of char avoiding its decomposition at the end of the test when the flame is vanished and pyrolysis becomes aerobic.

TEEP, DEEP and DEEP-Ph thermosets show a slightly lower pHRR (about $600 \mathrm{~kW} / \mathrm{m}^{2}$ ) but a much lower THR (9-10 kJ/g) associated to enhanced charring (30-40 wt.\%, slightly lower than values measured in TGA or PCFC).

Lastly, the residues are expanded for eugenol-containing epoxy materials, contrarily to residues from DGEBA and TECP thermosets (see Figure 8). The presence of the phosphorus function bonded to the epoxy network promotes the char as our team have already noted [42].

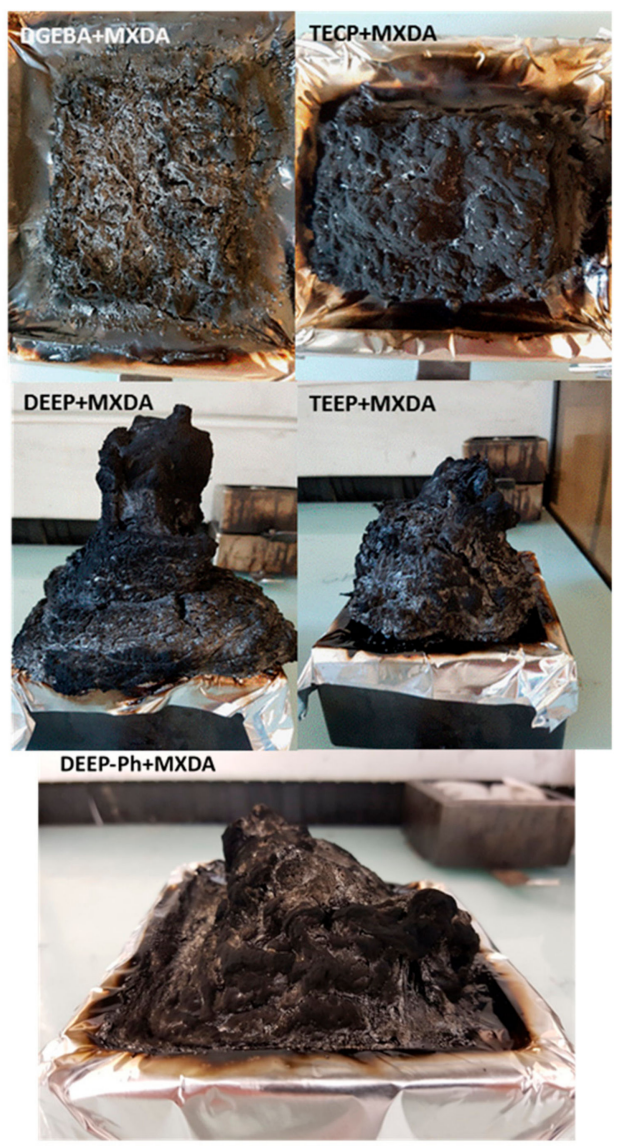

Figure 8. Pictures of residues from cone calorimeter tests.

Undoubtedly, eugenol leads to better flame retardancy properties than cardanol. This must be assigned to the aliphatic chains of cardanol. These chains are surely unfavorable to char promotion and contain a high amount of carbon, contributing to heat release. But their presence also leads directly to a lower phosphorus content in the materials. As reported in Tables 2 and 3, char content seems to roughly depend on phosphorus content.

As for PCFC, a slight difference is observed between TEEP, DEEP and DEEP-Ph thermosets. Phosphate and phosphonate groups are both equally efficient to promote char and reduce flammability. The influence of functionality (comparison between TEEP and DEEP materials) is not clear and may be counterbalanced by the higher phosphorus content of DEEP thermoset.

An interesting result concerns the influence of phosphorus on gas-phase mechanisms. Indeed, the effect heat of combustion (EHC) parameter highlighted the efficiency of the phosphorus radicals from phosphonate in the gas phase compared to the phosphate ones. Furthermore, while the char contents in the cone calorimeter and at a microscale (PCFC or TGA) are roughly similar, combustion efficiency $X$ can be properly calculated as the ratio between EHC and the heat of complete combustion measured in PCFC. The combustion efficiency is around 0.8 for the DGEBA thermoset, which corresponds to quite 
well-ventilated combustion. Combustion efficiency decreases for phosphorus-containing thermosets, a little (almost non-significant) reduction was observed for DEEP and TEEP. The reduction is slightly more significant for DEEP and mostly DEEP-Ph (a 30\% decrease was obtained for this last thermoset). This parameter $X$ may be ascribed to the flame inhibition effect, which is quite uncommon for phosphate groups. Indeed, phosphorus with a high oxidation degree is known to act mainly or exclusively as a char promoter [29]. Alternately, Braun et al. explained that the influence of phosphonate on the inhibition flame was equivalent to phosphinate (less oxidation degree of phosphorus) [32], which corresponded to the phosphorus vaporization potential during pyrolysis. These results show the same trend with a good compromise of phosphonate function between actions in both gas and condensed phases.

To confirm a flame inhibition effect, $\mathrm{CO} / \mathrm{CO}_{2}$ ratio was drawn versus heat release rate during intense burning (i.e., when HRR $>200 \mathrm{~kW} / \mathrm{m}^{2}$ ) to avoid to take into account the oxidative decomposition of char at lower temperature at the end of the test (Figure $7 \mathrm{~B}$ ). The $\mathrm{CO} / \mathrm{CO}_{2}$ ratio is very low for DGEBA thermoset but increases for phosphorus-containing materials. The highest values are reached for DEEP and DEEP-Ph. This confirms the incomplete combustion of these materials, and therefore the flame inhibition effect of phosphorus groups.

Residues from cone calorimeter tests were analyzed in detail. Figure 9 shows SEM pictures of residues in bulk, except for DGEBA thermoset (because the residue is only a thin and non-expanded layer). In all other cases, residues are highly porous and appear as interconnected pores with thin walls. TEEP thermoset exhibits filamentous structures. Nevertheless, for TECP and especially DEEP thermosets, the walls are much thicker. Note that it is difficult to confirm these structures are fully representative for the whole residues due to their heterogeneous appearance.

Table 4 shows the elemental composition of these residues. A large sample was picked up, ground and analyzed in each case. The DGEBA reference shows the presence of carbon and oxygen. Carbon content decreases for phosphorus-containing thermosets and oxygen content increases. The phosphorus content is significantly different according to the residues. Residue from TECP, which contains initially only 2.4 wt.\% of phosphorus exhibits the lowest content (8.7 wt.\%). Nevertheless, residue from TEEP exhibits the highest content (11.7 wt.\%) while TEEP thermoset has an intermediate phosphorus content (4.5 wt.\%). Note that DEEP and DEEP-Ph have the same initial phosphorus content but residues do not show the same composition. This evidences that the composition does not depend only on the initial phosphorus content. It is also noteworthy that the oxygen content increases together with phosphorus content, as already observed in a previous work [46].

Table 4. Elemental composition of residues.

\begin{tabular}{cccc}
\hline & C (wt.\%) & O (wt.\%) & P (wt.\%) \\
\hline DGEBA & $82.1( \pm 0.9)$ & $17.3( \pm 0.6)$ & $/$ \\
TECP & $66.1( \pm 0.4)$ & $24.3( \pm 0.1)$ & $8.7( \pm 0.2)$ \\
TEEP & $58.3( \pm 0.2)$ & $29.6( \pm 0.1)$ & $11.7( \pm 0.1)$ \\
DEEP & $68.1( \pm 0.1)$ & $22.4( \pm 0.3)$ & $9.2( \pm 0.0)$ \\
DEEP-Ph & $62.0( \pm 0.1)$ & $26.1( \pm 0.0)$ & $11.3( \pm 0.2)$ \\
\hline
\end{tabular}

Considering the initial and final phosphorus contents (in the sample and in the residue) and the residue content, it is possible to calculate the fraction of phosphorus remaining in the residue after cone calorimeter. Figure 10 highlights that all the phosphorus content remains in condensed phase in the case of the thermoset based on TEEP. For the three other thermosets, the fraction of phosphorus remaining in condensed phase is close, between 0.55 and 0.65 . This may be assigned to the trifunctionality of TEEP while DEEP and DEEP-Ph contain only two epoxy groups. For TECP, the long aliphatic chains of cardanol are detrimental and can explain why almost half of the phosphorus amount is released in the gas phase. Note also that the release of a significant fraction of phosphorus in gas phase is consistent with the flame inhibition effect previously proposed for DEEP and DEEP-Ph thermosets. 


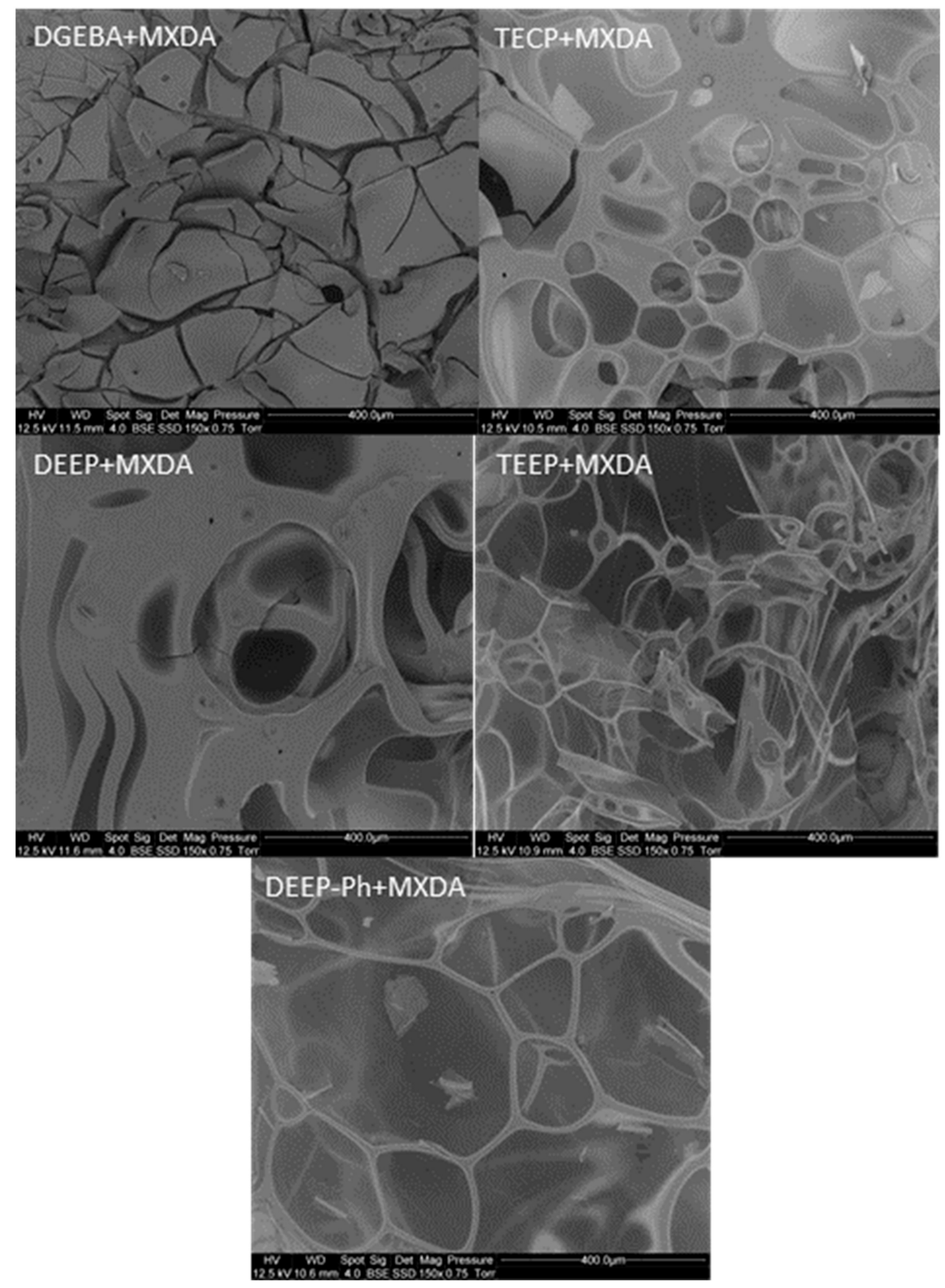

Figure 9. SEM pictures of residues from cone calorimeter. 


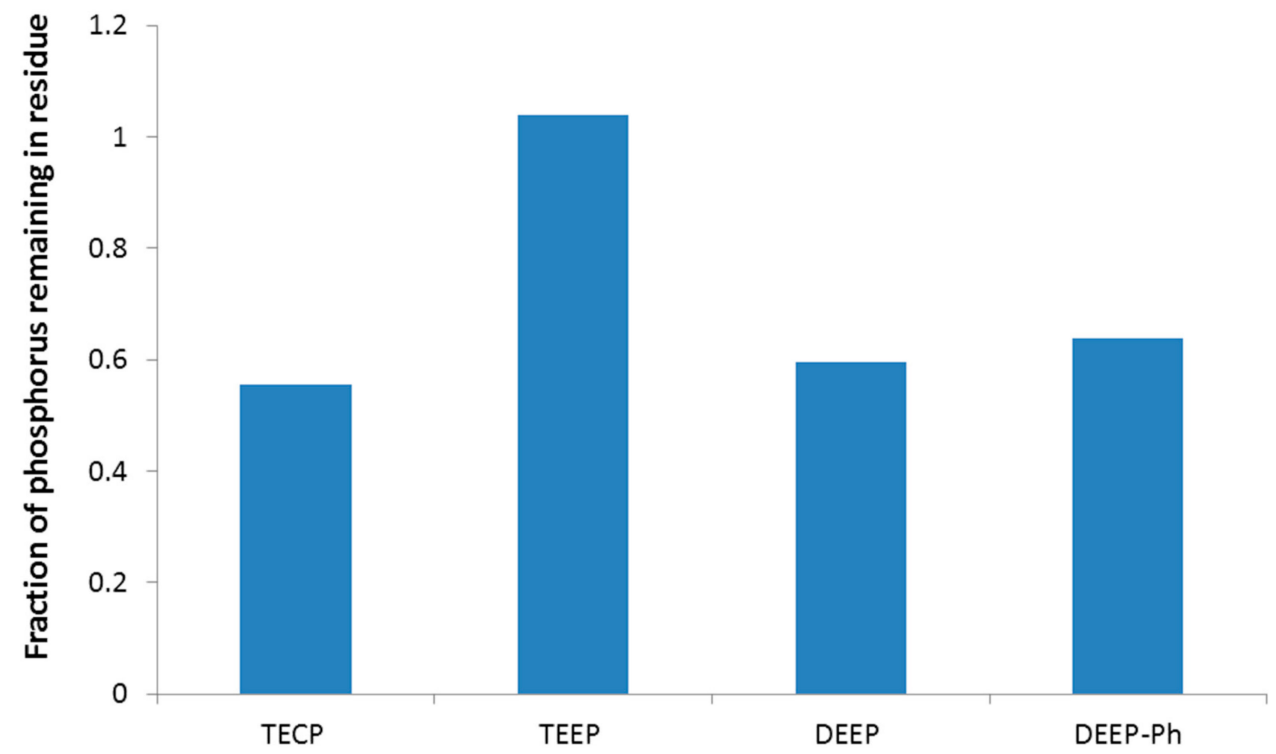

Figure 10. Fraction of phosphorus remaining in residue.

\section{Experimental Part}

\subsection{Materials}

Eugenol, phosphorus oxychloride, triethylamine, meta-chloroperoxybenzoic acid (m-CPBA) (77\%), dichlorophenylphosphine oxide, phenyl dichlorophosphate, hydrogen peroxide (30\% aqueous), formic acid and $p$-toluenesulfonic acid (PTSA) were purchased from Sigma Aldrich Merck (Darmstadt, Germany). Cardanol (Cardolite ${ }^{\circledR}$ NX-2026) was purchased from Cardolite (Mariakerke, Belgium). Meta-xylylenediamine (MXDA) was obtained from CTP (Russelsheim, Germany). All materials were used as received. Deuterated solvent $\mathrm{CDCl}_{3}$ was obtained from Eurisotop for NMR study. Ethyl acetate (EtOAc), pentane and toluene were purchased from Sigma-Aldrich.

\subsection{Methods}

NMR analyses Proton and carbon Nuclear Magnetic Resonance ( ${ }^{1} \mathrm{H}$ and $\left.{ }^{31} \mathrm{P} \mathrm{NMR}\right)$ analyses were performed in deuterated chloroform $\left(\mathrm{CDCl}_{3}\right)$ using a Bruker Avance $400 \mathrm{MHz}$ NMR spectrometer at a temperature of $25{ }^{\circ} \mathrm{C}$. NMR samples were prepared as follows: $10 \mathrm{mg}$ of product for ${ }^{1} \mathrm{H}$ experiment in around $0.4 \mathrm{~mL}$ of $\mathrm{CDCl}_{3}$. The chemical shifts were reported in part per million relative to tetramethylsilane. Spin multiplicity is shown by s $=$ singlet, $\mathrm{d}=$ doublet, $\mathrm{t}=$ triplet, $\mathrm{m}=$ multiplet.

Thermogravimetric Analyses (TGA) were performed using a TG 209F1 apparatus (Netzsch) at a heating rate of $20^{\circ} \mathrm{C} / \mathrm{min}$. Approximately $10 \mathrm{mg}$ of sample was placed in a platinum crucible and heated from room temperature to $900{ }^{\circ} \mathrm{C}$ under nitrogen atmosphere $(60 \mathrm{~mL} / \mathrm{min})$.

Differential Scanning Calorimetry (DSC) analyses were carried out using a NETZSCH DSC200F3 calorimeter. Constant calibration was performed using indium, $n$-octadecane and $n$-octane standards. Nitrogen was used as the purge gas. Approximately $10 \mathrm{mg}$ of sample were placed in perforated aluminum pans and the thermal properties were recorded between $-100{ }^{\circ} \mathrm{C}$ and $200{ }^{\circ} \mathrm{C}$ for the tri(epoxized-eugenyl)phosphate (TEEP) and tri(epoxized-cardanyl)phosphate (TECP)-based materials and from $25^{\circ} \mathrm{C}$ to $250{ }^{\circ} \mathrm{C}$ for the di(epoxized-eugenyl)phosphonate (DEEP)-based material at $20^{\circ} \mathrm{C} / \mathrm{min}$ to observe the glass transition temperature. The $\mathrm{T}_{\mathrm{g}}$ values were measured on the second heating ramp to erase the thermal history of the polymer. All the reported temperatures are mean values.

Dynamic mechanical analyses (DMA) were carried out on Metravib DMA 25 with Dynatest 6.8 software. Samples were tested according to uniaxial tension mode while heating at a rate of $3{ }^{\circ} \mathrm{C} / \mathrm{min}$ from $\approx \mathrm{T}_{\mathrm{g}}-100{ }^{\circ} \mathrm{C}$ to $\mathrm{T}_{\mathrm{g}}+100{ }^{\circ} \mathrm{C}$, at a frequency of $1 \mathrm{~Hz}$ with a fixed strain of $10^{-5} \mathrm{~m}$. These conditions 
have been chosen to study the elastic behavior of the materials. All the thermosets were analyzed at least two times for repeatability.

Titration of the epoxy equivalent weight by ${ }^{1} \mathrm{H}$ NMR The Epoxy Equivalent Weight (EEW) is the amount of product needed for one equivalent of reactive epoxy function. It was determined by ${ }^{1} \mathrm{H}$ NMR using an internal standard (benzophenone). A known weight of product and benzophenone was poured into an NMR tube and $500 \mu \mathrm{L}$ of $\mathrm{CDCl}_{3}$ were added. It was determined using Equation (1) by comparing the integral of the protons of the benzophenone and the integral of the epoxy moiety.

$$
\mathrm{EEW}=\frac{\int \mathrm{PhCOPh} \times \mathrm{H}_{\text {epoxy }}}{\int \text { epoxy } \times \mathrm{H}_{\text {PhCOPh }}} \times \frac{\mathrm{m}_{\text {epoxy }}}{\mathrm{m}_{\text {PhCOPh }}} \times \mathrm{M}_{\text {PhCOPh }},
$$

where $\int \mathrm{PhCOPh}$ is the integration of the benzophenone protons; $\int$ epoxy is the integration of the protons of the epoxy function; $\mathrm{H}_{\text {epoxy }}$ refers to the number of protons of the epoxy function; $\mathrm{H}_{\mathrm{PhCOPh}}$ is the number of protons of the benzophenone; $\mathrm{m}_{\mathrm{epoxy}}$ is the weight of the product; $\mathrm{m}_{\mathrm{PhCOPh}}$ refers to the weight of the benzophenone, $\mathrm{M}_{\mathrm{PhCOPh}}$ is the molecular weight of the benzophenone.

Cross-linking density from rubber elasticity theory $[39,40]$, the uniaxial stretching was studied on the rubbery plateau at $\mathrm{T}>\mathrm{T}_{\alpha}+50\left(\mathrm{~T}=150^{\circ} \mathrm{C}\right.$ for TEEP, DEEP and DGEBA and $\mathrm{T}=100^{\circ} \mathrm{C}$ for TECP), and at very small deformations. Under these hypotheses, the cross-linking density $\left(v^{\prime}\right)$, can be obtained from Equation (2), where $\mathrm{E}^{\prime}$ is the storage modulus, $\mathrm{R}$ is gas constant and $\mathrm{T}_{\alpha}$ is the temperature, in $\mathrm{K}$, of the transition from vitreous to rubber domain of material determined at the maximum of the $\tan \delta$ curve. Calculated values are given for information purposes only, and they can only be compared.

$$
v^{\prime}=\frac{E_{\mathrm{atT} \alpha+50}^{\prime}}{3 \mathrm{RT}_{\alpha+50}}
$$

Swelling index three samples of around $30 \mathrm{mg}$ each were separately put in THF for $24 \mathrm{~h}$. The swelling index (SI) was calculated using the Equation (3) where $\mathrm{m}_{2}$ is the mass of the material after swelling in THF and $\mathrm{m}_{1}$ is the initial mass of the material.

$$
\mathrm{SI}=\frac{\mathrm{m}_{2}-\mathrm{m}_{1}}{\mathrm{~m}_{1}} \times 100
$$

For the gel content after SI measurements, three samples were dried in a ventilated oven at $70{ }^{\circ} \mathrm{C}$ for $24 \mathrm{~h}$. The gel content (GC) was calculated using the Equation (4), where $\mathrm{m}_{3}$ is the mass of the material after drying and $\mathrm{m}_{1}$ is the initial mass of the material.

$$
\mathrm{GC}=\frac{\mathrm{m}_{3}}{\mathrm{~m}_{1}} \times 100,
$$

Pyrolysis combustion flow calorimeter flammability was first investigated using a pyrolysis combustion flow calorimeter which was developed by Lyon and Walters [47]. The sample ( $3 \pm 0.5 \mathrm{mg})$ was first heated from 80 to $750^{\circ} \mathrm{C}$ at $1^{\circ} \mathrm{C} / \mathrm{s}$ in a pyrolyzer under nitrogen flow and the degradation products were sent to a combustor where they were mixed with oxygen in excess at $900^{\circ} \mathrm{C}$. In such conditions, these products were fully oxidized. The heat release rate (HRR) was then calculated by oxygen depletion according to Huggett's relation (1 kg of consumed oxygen corresponds to $13.1 \mathrm{MJ}$ of released energy) [48].

Cone calorimeter fire behavior was also studied using a cone calorimeter (fire testing technology) which is a powerful tool to investigate the fire behavior of polymers at bench scale. Samples were previously conditioned away from air and moisture. A horizontal sample sheet of $70 \times 80 \times 2 \mathrm{~mm}^{3}$ was placed at $2.5 \mathrm{~cm}$ below a conic heater and isolated by rock wool. Plates were wrapped in aluminum foil but no retained frame was used. The samples were exposed to a heat flux of $35 \mathrm{~kW} / \mathrm{m}^{2}$ in well-ventilated conditions (air rate $24 \mathrm{~L} / \mathrm{s}$ ) in the presence of a spark igniter to force the ignition. HRR was determined according to oxygen depletion (Huggett's relation) as in the pyrolysis combustion 
flow calorimeter (PCFC). Note that the dimensions of samples are not standard and their masses are quite low. The standard deviations of cone calorimeter measurements are around $15 \%$.

Scanning electron microscopy coupled with energy-dispersive X-ray spectroscopy (SEM-EDX). The bulk structure of residues was observed using an SEM microscope (FEI Quanta 200 SEM). Elemental composition was analyzed with energy-dispersive X-ray detector (Oxford) coupled with the SEM microscope. For each residue, three analyses were carried out. Note that in the case of reference epoxy, residue is not expanded and only the surface was analyzed.

\subsection{Monomers/Polymers Syntheses}

\subsubsection{Synthesis of Trieugenylphosphate (TEP)}

The synthesis of TEP is described as follows: Eugenol $(10 \mathrm{~g}, 61 \mathrm{mmol})$ and triethylamine $(6.2 \mathrm{~g}$, $61 \mathrm{mmol})$ was solubilized in ethyl acetate $(100 \mathrm{~mL})$. Phosphorus oxychloride $(3.12 \mathrm{~g}, 20 \mathrm{mmol})$ was added dropwise, at $0{ }^{\circ} \mathrm{C}$, to the solution. The reaction mixture was stirred at room temperature for $24 \mathrm{~h}$. When the reaction was complete, the mixture was diluted with $100 \mathrm{~mL}$ of ethyl acetate and washed three times with $100 \mathrm{~mL}$ of deionized (DI) water and one time with brine solution $(100 \mathrm{~mL})$. The organic layer was dried with anhydrous magnesium sulfate and filtered. The filtrate was purified by silica gel chromatography (8:2 Pentane:EtOAc) to give $10.6 \mathrm{~g}$ of TEP as yellow oil (97\% yield).

${ }^{1} \mathrm{H} \mathrm{NMR}\left(400 \mathrm{MHz}, \mathrm{CDCl}_{3}\right): \delta(\mathrm{ppm}) 7.31(1 \mathrm{H}, \mathrm{dd}, J=1.4$ and $8.2 \mathrm{~Hz}) ; 6.67-6.76(2 \mathrm{H}, \mathrm{m}) ; 5.87-5.99(1 \mathrm{H}$, m); 5.03-5.14 (2H, m); $3.75(3 \mathrm{H}, \mathrm{s}) ; 3.34(2 \mathrm{H}, \mathrm{d}, J=6.7 \mathrm{~Hz})$.

${ }^{31} \mathrm{P}$ NMR (162 MHz, $\left.\mathrm{CDCl}_{3}, \mathrm{TMS}\right):-15.78$.

\subsubsection{Synthesis of Tricardanylphosphate (TCP)}

The synthesis of TCP is described previously with: cardanol (50 g, $166 \mathrm{mmol})$, triethylamine (22.4 mL, $166 \mathrm{mmol})$, ethyl acetate $(410 \mathrm{~mL})$ and phosphorus oxychloride $(15.3 \mathrm{~mL}, 55 \mathrm{mmol})$. Purification: silica gel chromatography (9:1 Pentane:EtOAc) to give $40 \mathrm{~g}$ of TCP as yellow oil (73\% yield).

${ }^{1} \mathrm{H}$ NMR $\left(400 \mathrm{MHz}, \mathrm{CDCl}_{3}\right): \delta(\mathrm{ppm}) 7.21-7.25(1 \mathrm{H}, \mathrm{m}) ; 6.98-7.08(3 \mathrm{H}, \mathrm{m}) ; 5.76-5.88(0.46 \mathrm{H}, \mathrm{m})$; 5.27-5.49 (4.1H, m); 4.94-5.10 (1H, m); 2.75-2.88 (2.4H, m); 2.54-2.63 (2.4H, m); 1.94-2.12 (4.4H, m); $1.52-1.66(2.5 \mathrm{H}, \mathrm{m}) ; 1.16-1.45(17.4 \mathrm{H}, \mathrm{m}) ; 0.84-0.96(2.7 \mathrm{H}, \mathrm{m})$.

${ }^{31} \mathrm{P}$ NMR (162 MHz, $\left.\mathrm{CDCl}_{3}, \mathrm{TMS}\right):-17.66$.

\subsubsection{Synthesis of Dieugenylphosphate (DEP)}

The synthesis of DEP is described previously with: eugenol $(50 \mathrm{~g}, 305 \mathrm{mmol})$, triethylamine $(41 \mathrm{~mL}$, $305 \mathrm{mmol})$, ethyl acetate $(750 \mathrm{~mL})$ and phenyl dichlorophosphate $(22 \mathrm{~mL}, 152 \mathrm{mmol})$. Purification: silica gel chromatography (8:2 Pentane:EtOAc) to give $16 \mathrm{~g}$ of DEP as yellow oil ( $24 \%$ yield).

${ }^{1} \mathrm{H}$ NMR (400 MHz, $\left.\mathrm{CDCl}_{3}\right): \delta(\mathrm{ppm})$ 7.33-7.39 (4H, m); 7.17-7.25 (3H, m); 6.68-6.82 (4H, m); 5.90-6.00 $(2 \mathrm{H}, \mathrm{m}) ; 5.04-5.16(4 \mathrm{H}, \mathrm{m}) ; 3.76(6 \mathrm{H}, \mathrm{s}) ; 3.37(4 \mathrm{H}, \mathrm{d}, J=6.9 \mathrm{~Hz})$.

${ }^{31} \mathrm{P}$ NMR (162 MHz, $\left.\mathrm{CDCl}_{3}, \mathrm{TMS}\right):-12.82$.

\subsubsection{Synthesis of Dieugenylphosphonate (DEP-Ph)}

The synthesis of DEP-Ph is described previously with: eugenol ( $34 \mathrm{~g}, 207 \mathrm{mmol})$, triethylamine $(28 \mathrm{~mL}, 207 \mathrm{mmol})$, ethyl acetate $(512 \mathrm{~mL})$ and phenylphosphonic dichloride $(20 \mathrm{~mL}, 103 \mathrm{mmol})$. Purification: silica gel chromatography (8:2 Pentane:EtOAc) to give $24 \mathrm{~g}$ of DEP-Ph as a white solid (52\% yield).

${ }^{1} \mathrm{H}$ NMR (400 MHz, $\left.\mathrm{CDCl}_{3}\right): \delta(\mathrm{ppm})$ 8.0-8.10 (2H, m); 7.42-7.59 (3H, m); $7.17(2 \mathrm{H}, \mathrm{dd}, J=1.7$ and 8.2 $\mathrm{Hz}) ; 6.64-6.72(4 \mathrm{H}, \mathrm{m}) ; 5.84-5.99(2 \mathrm{H}, \mathrm{m}) ; 4.98-5.10(4 \mathrm{H}, \mathrm{m}) ; 3.68(6 \mathrm{H}, \mathrm{s}) ; 3.32(4 \mathrm{H}, \mathrm{d}, J=6.7 \mathrm{~Hz})$. 
${ }^{31} \mathrm{P}$ NMR (162 MHz, $\left.\mathrm{CDCl}_{3}, \mathrm{TMS}\right): 12.94$.

\subsubsection{Synthesis of Tri(epoxized-eugenyl)phosphate (TEEP)}

TEEP was synthesized as follows. A solution of TEP $(10.2 \mathrm{~g}, 19 \mathrm{mmol})$ in ethyl acetate $(50 \mathrm{~mL})$ was added dropwise to a cooled suspension of meta-chloroperbenzoïc acid (m-CPBA 77\%) (14 g, $62.7 \mathrm{mmol}$ ) in ethyl acetate $(200 \mathrm{~mL})$. The reaction mixture was stirred at room temperature for $24 \mathrm{~h}$. The organic layer was washed several times with saturated sodium bicarbonate, brine and deionized water. The organic layer was dried with anhydrous magnesium sulfate and filtered. The filtrate was distilled under vacuum and purified by column chromatography (Pentane/EtOAc 50:50) to afford $10.3 \mathrm{~g}$ of TEEP as brown viscous oil (93\% yield).

${ }^{1} \mathrm{H}$ NMR (400 MHz, CDCl 3 , TMS): $\delta$ (ppm) 7.30-7.37 (1H, m); 6.73-6.87 (2H, m); 3.78 (3H, s); 3.10-3.16 $(1 \mathrm{H}, \mathrm{m}) ; 2.75-2.96(3 \mathrm{H}, \mathrm{m}) ; 2.53(1 \mathrm{H}, \mathrm{dd}, J=2.7$ and $4.9 \mathrm{~Hz})$.

${ }^{31} \mathrm{P}$ NMR (162 MHz, $\left.\mathrm{CDCl}_{3}, \mathrm{TMS}\right):-15.92$.

\subsubsection{Synthesis of Tri(epoxized-cardanyl)phosphate (TECP)}

TECP was synthesized as follows: A solution of TCP $(10 \mathrm{~g}, 10.5 \mathrm{mmol})$, formic acid $(360 \mu \mathrm{L}$, $9.5 \mathrm{mmol}), p$-toluenesulfonic acid $(180 \mathrm{mg}, 0.38 \mathrm{mmol})$ in toluene or EtOAc $(4 \mathrm{~mL})$ was heated to $50^{\circ} \mathrm{C}$. Then, a hydrogen peroxide solution $\left(30 \%(w / w)\right.$ in $\left.\mathrm{H}_{2} \mathrm{O}\right)(11 \mathrm{~g}, 32.3 \mathrm{mmol})$ was added dropwise. The reaction mixture was stirred at $65^{\circ} \mathrm{C}$ for $24 \mathrm{~h}$. The organic layer was washed several times with saturated sodium bicarbonate, brine and deionized water. The organic layer was dried with anhydrous magnesium sulfate and filtered. The filtrate was distilled under vacuum and purified by column chromatography (Pentane/EtOAc 8:2).

${ }^{1} \mathrm{H}$ NMR $\left(400 \mathrm{MHz}, \mathrm{CDCl}_{3}\right): \delta(\mathrm{ppm})$ 7.18-7.25 (1H, m); 6.97-7.06 (3H, m); 5.74-5.94 (0.30H, m); 5.4-5.62 $(0.29 \mathrm{H}, \mathrm{m}) ; 4.95-5.22(0.56 \mathrm{H}, \mathrm{m}) ; 3.03-3.21(0.80 \mathrm{H}, \mathrm{m}) ; 2.86-3.01(1.58 \mathrm{H}, \mathrm{m}) ; 2.57(2 \mathrm{H}, \mathrm{t}, J=7.8 \mathrm{~Hz})$; $2.14-2.45(0.83 \mathrm{H}, \mathrm{m}) ; 1.69-1.85(0.68 \mathrm{H}, \mathrm{m}) ; 1.18-1.67(18.1 \mathrm{H}, \mathrm{m}) ; 0.82-1.03(2.03 \mathrm{H}, \mathrm{m})$.

${ }^{31} \mathrm{P}$ NMR (162 MHz, $\left.\mathrm{CDCl}_{3}, \mathrm{TMS}\right):-17.65$.

\subsubsection{Synthesis of Di(epoxized-eugenyl)phosphate (DEEP)}

The synthesis of DEEP is described previously with: DEP (16 g, $35 \mathrm{mmol}), m$-CPBA (16 g, $70 \mathrm{mmol})$ and ethyl acetate $(430 \mathrm{~mL})$. Purification: silica gel chromatography (2:8 Pentane:EtOAc) to give $11 \mathrm{~g}$ of DEEP as yellow oil (65\% yield).

${ }^{1} \mathrm{H}$ NMR $\left(400 \mathrm{MHz}, \mathrm{CDCl}_{3}\right): \delta(\mathrm{ppm}) 7.35-7.39(4 \mathrm{H}, \mathrm{m}) ; 7.19-7.27(3 \mathrm{H}, \mathrm{m}) ; 6.77-6.88(4 \mathrm{H}, \mathrm{m}) ; 3.79(6 \mathrm{H}$, s); 3.13-3.19 (2H, m); 2.80-2.89 (6H, m); $2.56(2 \mathrm{H}, \mathrm{dd}, J=2.7$ and $5.0 \mathrm{~Hz})$.

${ }^{31} \mathrm{P}$ NMR (162 MHz, $\left.\mathrm{CDCl}_{3}, \mathrm{TMS}\right):-16.52$.

\subsubsection{Synthesis of Di(epoxized-eugenyl)phosphonate (DEEP-Ph)}

The synthesis of DEEP-Ph is described previously with: DEP-Ph $(24 \mathrm{~g}, 53 \mathrm{mmol}), m$-CPBA $(29.5 \mathrm{~g}$, $117 \mathrm{mmol}$ ) and ethyl acetate $(680 \mathrm{~mL})$. Purification: silica gel chromatography (2:8 Pentane:EtOAc) to give $14 \mathrm{~g}$ of DEEP-Ph as a white solid (55\% yield).

${ }^{1} \mathrm{H}$ NMR $\left(400 \mathrm{MHz}, \mathrm{CDCl}_{3}\right): \delta(\mathrm{ppm})$ 8.04-8.12 (2H, m), 7.48-7.64 (3H, m); $7.21(2 \mathrm{H}, \mathrm{dd}, J=1.5$ and 8.0 $\mathrm{Hz}) ; 6.72-6.83(4 \mathrm{H}, \mathrm{m}) ; 3.75(6 \mathrm{H}, \mathrm{s}) ; 3.12-3.18(2 \mathrm{H}, \mathrm{m}) ; 2.78-2.86(6 \mathrm{H}, \mathrm{m}) ; 2.55(2 \mathrm{H}, \mathrm{ddd}, J=0.8,2.6$ and $5.0 \mathrm{~Hz})$.

\footnotetext{
${ }^{31} \mathrm{P}$ NMR (162 MHz, $\left.\mathrm{CDCl}_{3}, \mathrm{TMS}\right): 13.00$.
} 


\subsubsection{Epoxy Network Curing Protocol}

Several formulations were carried out using TEEP, TECP, DEEP, DEEP-Ph, DGEBA and MXDA. In order to prepare the materials, the mass of amine was calculated using the Equation (5). The Amine Hydrogen Equivalent Weight (AHEW) and the Epoxy Equivalent Weight represent the amount of product needed for one equivalent of reactive function.

$$
m_{\text {amine }}=\frac{A H E W_{\text {amine }} \times m_{\text {epoxy }}}{E E W},
$$

The materials were synthesized with a molar ratio epoxy/amine of 2:1. Indeed, two epoxy groups react with each hydrogen of the primary amine. The amine and the epoxy were stirred using a speedmixer under vacuum and then the homogeneous mixture obtained was put in an aluminum mold for three hours at $80^{\circ} \mathrm{C}$ and then cured at $150^{\circ} \mathrm{C}$ for one hour for the eugenol derivatives, while for the cardanol derivative the mixture was heated at $120^{\circ} \mathrm{C}$ overnight and then cured at $150{ }^{\circ} \mathrm{C}$ for three hours. Sheets of $7 \times 8 \mathrm{~cm}^{2}$ have been synthetized to characterize flame retardant properties.

\section{Conclusions}

In this paper, we synthesized four biobased epoxy monomers from cardanol and eugenol without using BPA or epichlorohydrin. Four different thermosets have been obtained after curing with a benzylic amine (MXDA) and their thermo-mechanical properties have been compared to a petroleum-based epoxy thermoset coming from DGEBA. Due to the high aromatic density of eugenol-based materials, high glass transition temperatures are obtained whereas the long aliphatic chain of cardanol monomers leads to flexible thermosets with low $\mathrm{T}_{\mathrm{g}}$. These new eugenol-based thermosets exhibit good thermo-mechanical properties with high char yields. The thermal stability of these thermosets was finally characterized by TGA and their flame retardant properties by PCFC and cone calorimeter tests. The incorporation of phosphorus as a linker between phenols confers flame-retardant properties to the networks, without the use of flame-retardant additives. This reactive approach prevents the migration of flame-retardant additives out of the network. Furthermore, phosphonate or phosphate functions do not hang off the main chain of the network and are completely integrated to it. Hence, the incorporation of phosphorus leads to a significant decrease of flammability as evidenced by pHRR and THR values. Furthermore, eugenol lead to monomers with better flame retardant properties than cardanol which contains long aliphatic chain. This chain is unfavorable to the char promotion and contains high carbon amount, contributing to heat release. Furthermore, phosphate and phosphonate groups are both equally efficient to promote char and reduce flammability for these materials. Moreover the residues are expanded, contrarily to residues from DGEBA and TECP thermosets, relating to great intumescence properties. The flame inhibition effect was confirmed as an additional flame retardancy mode-of-action with a better efficiency for the phosphonate function. In conclusion, novel biobased aromatic monomers were synthesized, giving access to high performance thermosets with good thermal, thermo-mechanical and flame retardant properties.

Supplementary Materials: The following are available online, Figures S1-S12.

Author Contributions: All the authors conceived the experiments. Y.E., M.D., performed the synthesis and characterization experiments. R.S. achieved the fire characterizations of materials. Y.E., M.D. and R.S. wrote the manuscript. S.C. and C.N. corrected the manuscript. All the authors read and accepted the final manuscript.

Funding: This research received no external funding.

Acknowledgments: Loïc Dumazert is acknowledged for his help in the fire characterization of materials.

Conflicts of Interest: The authors declare no conflict of interest. 


\section{References}

1. Auvergne, R.; Caillol, S.; David, G.; Boutevin, B.; Pascault, J.P. Biobased Thermosetting Epoxy: Present and Future. Chem. Rev. 2014, 114, 1082-1115. [CrossRef] [PubMed]

2. Pascault, J.-P.; Williams, R.J.J. Epoxy Polymers: New Materials and Innovations; Wiley-VCH: Weinheim, Germany, 2010; p. 367.

3. Levchik, S.V.; Weil, E.D. Thermal decomposition, combustion and flame-retardancy of epoxy resins-A review of the recent literature. Polym. Int. 2004, 53, 1901-1929. [CrossRef]

4. Pham, H.Q.; Marks, M.J. Epoxy Resins. In Ullmann's Encyclopedia of Industrial Chemistry; Wiley-VCH: Weinheim, Germany, 2005.

5. Vom Saal, F.S.; Hughes, C. An extensive new literature concerning low-dose effects of bisphenol A shows the need for a new risk assessment. Envir. Health Perspect. 2005, 113, 926-933. [CrossRef]

6. Kuruto-Niwa, R.; Tateoka, Y.; Usuki, Y.; Nozawa, R. Measurement of bisphenol A concentrations in human colostrum. Chemosphere 2007, 66, 1160-1164. [CrossRef] [PubMed]

7. Jaillet, F.; Darroman, E.; Ratsimihety, A.; Auvergne, R.; Boutevin, B.; Caillol, S. New biobased epoxy materials from cardanol. Eur. J. Lipid Sci. Technol. 2014, 116, 63-73. [CrossRef]

8. Ng, F.F.; Couture, G.; Philippe, C.; Boutevin, B.; Caillol, S. Bio-Based Aromatic Epoxy Monomers for Thermoset Materials. Molecules 2017, 22, 149. [CrossRef] [PubMed]

9. Chrysanthos, M.; Galy, J.; Pascault, J.P. Preparation and properties of bio-based epoxy networks derived from isosorbide diglycidyl ether. Polymer 2011, 52, 3611-3620. [CrossRef]

10. Shibata, M.; Nakai, K. Preparation and Properties of Biocomposites Composed of Bio-Based Epoxy Resin, Tannic Acid, and Microfibrillated Cellulose. J. Polym. Sci. Part B-Polym. Phys. 2010, 48, 425-433. [CrossRef]

11. Baroncini, E.A.; Yadav, S.K.; Palmese, G.R.; Stanzione, J.F. Recent advances in bio-based epoxy resins and bio-based epoxy curing agents. J. Appl. Polym. Sci. 2016, 133. [CrossRef]

12. Fache, M.; Darroman, E.; Besse, V.; Auvergne, R.; Caillol, S.; Boutevin, B. Vanillin, a promising biobased building-block for monomer synthesis. Green Chem. 2014, 16, 1987-1998. [CrossRef]

13. Laurichesse, S.; Averous, L. Chemical modification of lignins: Towards biobased polymers. Prog. Polym. Sci. 2014, 39, 1266-1290. [CrossRef]

14. Mauck, J.R.; Yadav, S.K.; Sadler, J.M.; La Scala, J.J.; Palmese, G.R.; Schmalbach, K.M.; Stanzione, J.F. Preparation and Characterization of Highly Bio-Based Epoxy Amine Thermosets Derived from Lignocellulosics. Macromol. Chem. Phys. 2017, 218. [CrossRef]

15. Harvey, B.G.; Sahagun, C.M.; Guenthner, A.J.; Groshens, T.J.; Cambrea, L.R.; Reams, J.T.; Mabry, J.M. A High-Performance Renewable Thermosetting Resin Derived from Eugenol. Chemsuschem 2014, 7, 1964-1969. [CrossRef] [PubMed]

16. Wan, J.T.; Gan, B.; Li, C.; Molina-Aldareguia, J.; Kalali, E.N.; Wang, X.; Wang, D.Y. A sustainable, eugenol-derived epoxy resin with high biobased content, modulus, hardness and low flammability: Synthesis, curing kinetics and structure-property relationship. Chem. Eng. J. 2016, 284, 1080-1093. [CrossRef]

17. Koeduka, T.; Fridman, E.; Gang, D.R.; Vassao, D.G.; Jackson, B.L.; Kish, C.M.; Orlova, I.; Spassova, S.M.; Lewis, N.G.; Noel, J.P.; et al. Eugenol and isoeugenol, characteristic aromatic constituents of spices, are biosynthesized via reduction of a coniferyl alcohol ester. Proc. Natl. Acad. Sci. USA 2006, 103, 10128-10133. [CrossRef]

18. Faye, I.; Decostanzi, M.; Ecochard, Y.; Caillol, S. Eugenol bio-based epoxy thermosets: From cloves to applied materials. Green Chem. 2017, 19, 5236-5242. [CrossRef]

19. Lu, S.Y.; Hamerton, I. Recent developments in the chemistry of halogen-free flame retardant polymers. Prog. Polym. Sci. 2002, 27, 1661-1712. [CrossRef]

20. Lin, C.H.; Wu, C.Y.; Wang, C.S. Synthesis and properties of phosphorus-containing advanced epoxy resins. II. J. Appl. Polym. Sci. 2000, 78, 228-235. [CrossRef]

21. Wang, C.S.; Lin, C.H. Synthesis and properties of phosphorus-containing epoxy resins by novel method. J. Polym. Sci. Part A-Polym. Chem. 1999, 37, 3903-3909. [CrossRef]

22. Green, J. A review of phosphorus-containing flame retardants. J. Fire Sci. 1996, 14, 353-366. [CrossRef]

23. Levchik, S.; Piotrowski, A.; Weil, E.; Yao, Q. New developments in flame retardancy of epoxy resins. Polym. Degrad. Stab. 2005, 88, 57-62. [CrossRef] 
24. Weil, E.D.; Levchik, S. A review of current flame retardant systems for epoxy resins. J. Fire Sci. 2004, 22, 25-40. [CrossRef]

25. Pillai, C.K.S.; Prasad, V.S.; Sudha, J.D.; Bera, S.C.; Menon, A.R.R. Polymeric Resins from Renewable Resources. 2. Synthesis and Characterization of Flame-Retardant Prepolymers from Cardanol. J. Appl. Polym. Sci. 1990, 41, 2487-2501. [CrossRef]

26. Fu, X.L.; Wang, X.; Xing, W.Y.; Zhang, P.; Song, L.; Hu, Y. Two-dimensional cardanol-derived zirconium phosphate hybrid as flame retardant and smoke suppressant for epoxy resin. Polym. Degrad. Stab. 2018, 151, 172-180. [CrossRef]

27. Wazarkar, K.; Sabnis, A. Synergistic effect of P-S and crosslink density on performance properties of epoxy coatings cured with cardanol based multifunctional carboxyl curing agents. React. Funct. Polym. 2018, 128, 74-83. [CrossRef]

28. Miao, J.T.; Yuan, L.; Guan, Q.B.; Liang, G.Z.; Gu, A.J. Biobased epoxy resin derived from eugenol with excellent integrated performance and high renewable carbon content. Polym. Int. 2018, 67, 1194-1202. [CrossRef]

29. Schartel, B. Phosphorus-based Flame Retardancy Mechanisms-Old Hat or a Starting Point for Future Development? Materials 2010, 3, 4710-4745. [CrossRef]

30. Levchik, S.V.; Weil, E.D. A review of recent progress in phosphorus-based flame retardants. J. Fire Sci. 2006, 24, 345-364. [CrossRef]

31. Hergenrother, P.M.; Thompson, C.M.; Smith, J.G.; Connell, J.W.; Hinkley, J.A.; Lyon, R.E.; Moulton, R. Flame retardant aircraft epoxy resins containing phosphorus. Polymer 2005, 46, 5012-5024. [CrossRef]

32. Braun, U.; Balabanovich, A.I.; Schartel, B.; Knoll, U.; Artner, J.; Ciesielski, M.; Doring, M.; Perez, R.; Sandler, J.K.W.; Altstadt, V.; Hoffmann, T.; Pospiech, D. Influence of the oxidation state of phosphorus on the decomposition and fire behaviour of flame-retarded epoxy resin composites. Polymer 2006, 47, 8495-8508. [CrossRef]

33. Liu, Z.S.; Chen, J.; Knothe, G.; Nie, X.A.; Jiang, J.C. Synthesis of Epoxidized Cardanol and Its Antioxidative Properties for Vegetable Oils and Biodiesel. ACS Sustain. Chem. Eng. 2016, 4, 901-906. [CrossRef]

34. Scodeller, I.; Mansouri, S.; Morvan, D.; Muller, E.; Vigier, K.D.; Wischert, R.; Jerome, F. Synthesis of Renewable meta-Xylylenediamine from Biomass-Derived Furfural. Angew. Chem.-Int. Ed. 2018, 57, 10510-10514. [CrossRef]

35. Harvey, B.G.; Guenthner, A.J.; Lai, W.W.; Meylemans, H.A.; Davis, M.C.; Cambrea, L.R.; Reams, J.T.; Lamison, K.R. Effects of o-Methoxy Groups on the Properties and Thermal Stability of Renewable High-Temperature Cyanate Ester Resins. Macromolecules 2015, 48, 3173-3179. [CrossRef]

36. Hernandez, E.D.; Bassett, A.W.; Sadler, J.M.; La Scala, J.J.; Stanzione, J.F. Synthesis and Characterization of Bio-based Epoxy Resins Derived from Vanillyl Alcohol. ACS Sustain. Chem. Eng. 2016, 4, 4328-4339. [CrossRef]

37. Villanueva, M.; Martin-Iglesias, J.L.; Rodriguez-Anon, J.A.; Proupin-Castineiras, J. Thermal Study of an Epoxy System Dgeba ( $=$ 0)/Mxda Modified with Poss. J. Thermal. Anal. Calorim. 2009, 96, 575-582. [CrossRef]

38. Marks, M.J.; Snelgrove, R.V. Effect of Conversion on the Structure-Property Relationships of Amine-Cured Epoxy Thermosets. Acs Appl. Mat. Interfaces 2009, 1, 921-926. [CrossRef]

39. Levita, G.; De Petris, S.; Marchetti, A.; Lazzeri, A. Crosslink density and fracture toughness of epoxy resins. J. Mat. Sci. 1991, 26, 2348-2352. [CrossRef]

40. Schroeder, J.A.; Madsen, P.A.; Foister, R.T. Structure/property relationships for a series of crosslinked aromatic/aliphatic epoxy mixtures. Polymer 1987, 28, 929-940. [CrossRef]

41. Despinasse, M.C.; Schartel, B. Aryl phosphate-aryl phosphate synergy in flame-retarded bisphenol A polycarbonate/acrylonitrile-butadiene-styrene. Thermochim. Acta 2013, 563, 51-61. [CrossRef]

42. Ménard, R.; Negrell, C.; Ferry, L.; Sonnier, R.; David, G. Synthesis of biobased phosphorus-containing flame retardants for epoxy thermosets comparison of additive and reactive approaches. Polym. Degrad. Stab. 2015, 120, 300-312. [CrossRef]

43. Sonnier, R.; Otazaghine, B.; Ferry, L.; Lopez-Cuesta, J.M. Study of the combustion efficiency of polymers using a pyrolysis-combustion flow calorimeter. Combust. Flame 2013, 160, 2182-2193. [CrossRef] 
44. Sonnier, R.; Otazaghine, B.; Dumazert, L.; Menard, R.; Viretto, A.; Dumas, L.; Bonnaud, L.; Dubois, P.; Safronava, N.; Walters, R.; Lyon, R. Prediction of thermosets flammability using a model based on group contributions. Polymer 2017, 127, 203-213. [CrossRef]

45. Menard, R.; Negrell, C.; Fache, M.; Ferry, L.; Sonnier, R.; David, G. From a bio-based phosphorus-containing epoxy monomer to fully bio-based flame-retardant thermosets. Rsc Adv. 2015, 5, 70856-70867. [CrossRef]

46. Sonnier, R.; Dumazert, L.; Livi, S.; Nguyen, T.K.L.; Duchet-Rumeau, J.; Vahabi, H.; Laheurte, P. Flame retardancy of phosphorus-containing ionic liquid based epoxy networks. Polym. Degrad. Stab. 2016, 134, 186-193. [CrossRef]

47. Lyon, R.E.; Walters, R.N. Pyrolysis combustion flow calorimetry. J. Anal. Appl. Pyrol. 2004, 71, 27-46. [CrossRef]

48. Huggett, C. Estimation of Rate of Heat Release by Means of Oxygen-Consumption Measurements. Fire Mat. 1980, 4, 61-65. [CrossRef]

Sample Availability: Samples of the compounds are not available from the authors.

(C) 2019 by the authors. Licensee MDPI, Basel, Switzerland. This article is an open access article distributed under the terms and conditions of the Creative Commons Attribution (CC BY) license (http://creativecommons.org/licenses/by/4.0/). 